\title{
Investigation and prediction of slug flow characteristics in highly viscous liquid and gas flows in horizontal pipes
}

\author{
Y. Zhao ${ }^{1}$, L. Lao, and H. Yeung
}

Process Systems Engineering Group, Department of Offshore, Process and Energy Engineering, Cranfield University, Cranfield, MK43 OAL, United Kingdom

\begin{abstract}
:
Slug flow characteristics in highly viscous liquid and gas flow are studied experimentally in a horizontal pipe with $0.074 \mathrm{~m}$ ID and $17 \mathrm{~m}$ length. Results of flow regime map, liquid holdup and pressure gradient are discussed and liquid viscosity effects are investigated. Applicable correlations which are developed to predict liquid holdup in slug body for low viscosity flow are assessed with high viscosity liquids. Furthermore, a mechanistic model is developed for predicting the characteristics of slug flows of highly viscous liquid in horizontal pipes. A control volume is drawn around the slug body and slug film of a slug unit. Momentum equations with a momentum source term representing the significant momentum exchange between film zone and slug body are applied. Liquid viscosity effects are considered in closure relations. The mechanistic model is validated by comparing available pressure gradient and mean slug liquid holdup data produced in the present study and those obtained from literature, showing satisfactory capabilities over a large range of liquid viscosity.
\end{abstract}

Keywords: gas-liquid flow; high viscosity; slug flow; mechanistic model; horizontal pipe

\footnotetext{
${ }^{1}$ Corresponding author Email: yabin.zhao@cranfield.ac.uk Tel: +44 (0)1234 758254
}

Published by Elsevier. This is the Author Accepted Manuscript issued with: 


\section{Introduction}

Liquid and gas two-phase flow is a very common occurrence in processes of many industries including chemical, power generation, and petroleum. Flow characteristics of two phase flows have been studied for decades, and a variety of models for the prediction of the flow behaviours have been developed. However, new challenges have emerged, particularly for the oil and gas industries where high viscosity (typically more than $1000 \mathrm{cP}$ ) liquid and gas flows are increasingly involved. Liquid viscosities were found to significantly affect flow behaviours, such as flow patterns, liquid holdup, slug characteristics and wave behaviours at the interface between liquid and gas phases. Most published models are developed based on data from much less viscous liquids and their applicability to such viscous liquid and gas flows need to be ascertained.

Liquid viscosity effects have been revealed in several experimental studies. Taitel et al. (1986) conducted liquid and gas experiments in a horizontal pipe with liquid viscosities of $1 \mathrm{cP}, 90 \mathrm{cP}$ and $165 \mathrm{cP}$. They reported that their previous model (Taitel and Dukler, 1976) specifically for water and gas flow still showed good agreement for liquid with a viscosity of $165 \mathrm{cP}$. Andritsos et al. (1989) experimentally investigated effects of liquid viscosity on the transition from stratified to slug flow in a horizontal pipe. They proposed a new mechanism for slug initiation in which the slug formation occurred with the appearance of Kelvin-Helmholtz waves with a small wavelength. Their results showed slug flow tended to be stabilized with increasing liquid viscosity but interpretations were contradicted against long-wavelength inviscid analysis. Gokcal et al. (2006) investigated slightly higher liquid viscosity (up to $587 \mathrm{cP}$ ) and their results were compared with models developed by Xiao et al. (1990) and Zhang et al. (2003a). Results showed that these models can be improved with specific 
consideration on liquid viscosity. Marquez and Trujillo (2010) investigated flow characteristics with liquid viscosity of $10 \mathrm{cP}, 392 \mathrm{cP}$ and $1000 \mathrm{cP}$. Flow regime transitions tested at different viscosity clearly showed that the range of slug flow in the flow regime map was extended as liquid viscosity increased. A similar trend has been identified by Matsubara et al. (2011) who conducted experiments with high liquid viscosity of $11000 \mathrm{cP}$. Their results indicated that regions in the regime map for roll wave and stratified flow at low liquid viscosity were replaced by those for intermittent and annular flow. Viscous liquid slug flow also has particular features. It was characterized as a high frequency (Gokcal, et al., 2009b), a short length (AlSafran, et al., 2011), and a high liquid holdup both in slug body (Al-Safran et al., 2013) and in slug film region (Nädler and Mewes, 1995). Although a number of studies on the effect of viscosity on slug flows have been conducted, available experimental data and validated correlations for high viscosity (more than $1000 \mathrm{mPa}$ s) liquid and gas flow are still scarce.

Steady-state models for gas-liquid two phase flows have been developed for many years. Early developments were established on empirical or semi-empirical equations. These models heavily relied on fitting experimental and/or field data. Beggs and Brill (1973) developed a semi-empirical model for gas-liquid flow and investigated pipe inclination effects on liquid holdup and pressure loss. They found that liquid holdup had a strong dependence on pipe inclinations and could be calculated by correlations developed from experimental data for different flow patterns. To further understand the physics behind the complex flow behaviours, a mechanistic model was developed based on solving two-fluid continuity and momentum equations. The pioneer work was carried out by Taitel and Dukler (1976) who developed models for flow regime transitions in gas and liquid flow. The model 
is applicable for steady-state liquid and gas flow with a low liquid viscosity in horizontal and slightly horizontal pipes (i.e. $\pm 10^{\circ}$ ). Barnea (1987) extended Taitel and Dukler's works by considering different flow regime models and incorporated effects of fluid properties, pipe size and pipe inclinations. Since then, several mechanistic models were developed to predict not only flow regime transition, but also pressure and liquid holdup in each flow regime (Xiao, et al., 1990; Gomez et al., 1999). Particularly for slug flow, Xiao et al. (1990) applied the combined momentum equation for stratified flow to solve the equilibrium liquid film level in slug film region. Gomez et al. (1999) developed a mechanistic model to predict gas-liquid flow behaviours in wellbores and pipelines. Their model was validated by comparing not only with laboratory measurements but also with field data obtained from North Sea and Prudhoe Bay, Alaska. A good agreement in pressure drop was shown. But the combined momentum equation which was used in stratified flow is not sufficient to represent complex momentum exchanges in slug flow. Zhang et al. (2000, 2003a, b) developed a momentum equation using the entire liquid film as the control volume to incorporate the momentum exchange between slug body and film zone. Their model was evaluated by experimental results with low viscosity liquids (Zhang et al. 2003b) and liquids with a viscosity up to $587 \mathrm{cP}$ (Gokcal et al.2006). However, no validation works for the model were carried out for liquids which have a viscosity above 1000 $\mathrm{cP}$.

The objective of this paper is to investigate effects of liquid viscosity on slug flow characteristics. Experiments using liquid viscosity ranged from $1000 \mathrm{cP}$ to $6000 \mathrm{cP}$ are carried out in a $0.074 \mathrm{~m}$ ID and $17 \mathrm{~m}$ long horizontal pipe. Liquid viscosity effects on flow patterns, liquid holdup and pressure gradient are discussed. A mechanistic slug flow model is developed and liquid viscosity effects on parameters used in 
closure equations are evaluated. Experimental results and results from literature for pressure drop and mean liquid holdup over the slug unit are used to validate the model. Results show a good agreement for viscous liquids with a large viscosity range.

\section{Experiment set-up}

\subsection{Flow facility}

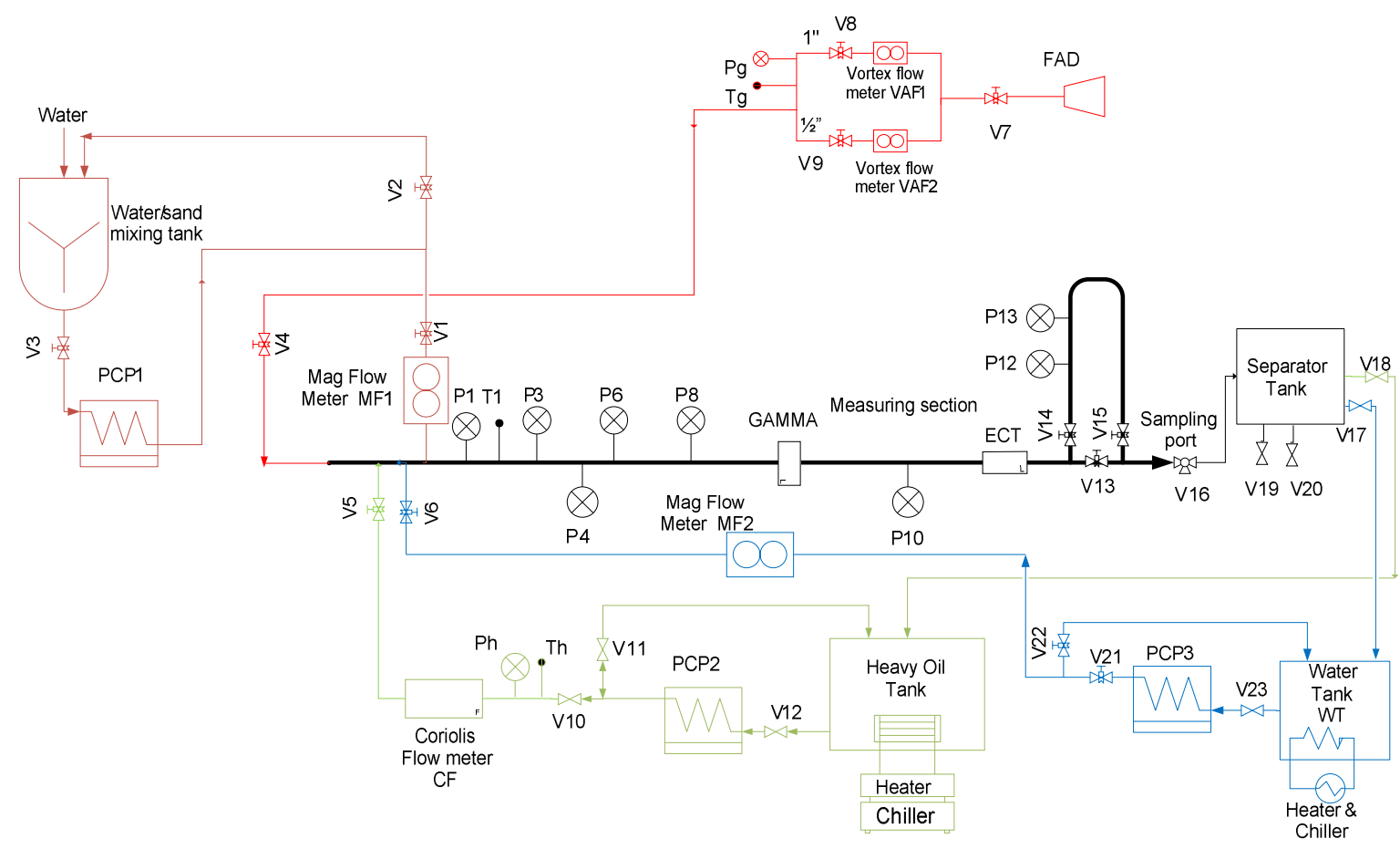

Figure 1 The schematic of experiment facility

A scale-up $0.074 \mathrm{~m}$ ID facility has been built in PSE lab in Cranfield University. As shown in Figure 1, this facility is a one-through facility and composed of a horizontal pipe with a length of $17 \mathrm{~m}$ long. A measure section is located at $14 \mathrm{~m}$ downstream from the inlet. A separator is settled at the end of the pipe, where the fluids are collected and separated.

High viscosity oil is stored in a tank with a capacity of $2 \mathrm{~m}^{3}$ and fed into the main pipe via a T-junction by a progressive cavity pump (PCP). At the inlet, oil flow rate is 
metered by a Coriolis flow meter (Endress+Hauser, Promass 83 F80 DN80), and circulated to the oil tank to maintain a uniformed viscosity before being injected into the main pipe. The air is supplied from a screw engineering compressor, which has a maximum supply capacity of $400 \mathrm{~m}^{3} / \mathrm{h}$ free air delivery and a maximum discharge pressure of 7 barg. The flow rates are measured by flow meters: 0.5 -inch vortex flow meter (Endress+Hauser Prowirl 72F15 DN15) and 1.5-inch vortex flow meter (Endress+Hauser Prowirl 72F40 DN40), which range from 0 20 and 10 130 $\mathrm{m}^{3} / \mathrm{h}$ respectively. At the end of the pipe, the mixture is collected in a separator where gas is ventilated. The oil stays for at least 48 hours until the gas is fully separated.

At the T-junction, oil and gas fluids are mixed and the flow starts to develop along the pipe. Measuring section is located at $14 \mathrm{~m}$ downstream where flow pattern are recorded, pressure are measured by pressure transducers which are installed along the pipe and data in different locations are acquired by the Labview system. Liquid holdup is measured by an electrical capacitance tomography (or ECT) system which is designed and manufactured by Industrial Tomography System (ITS), UK.

\subsection{Electrical capacitance tomography facility}

Potential benefits inherent in the Electrical Capacitance Tomography (ECT) system include: non-invasiveness and non-intrusiveness, robust, high speed imaging capability, low cost and radiation free. It is proved as a reliable approach in the measurement of very viscous liquid and gas flow. For example, Zorgani et al. (2009) investigated the static measurement for heavy oil and water mixtures by using ECT system; Zhang et al. (2010) used ECT system to identify flow pattern in viscous liquid and gas two-phase flow. 
The ECT system has 12 electrodes mounted externally and equally spaced around the pipe circumference. Prior to measurements a calibration run will be carried out in order to establish a scale of the display with different colour codes, representing different phases. The low reference result is obtained by setting empty pipe, and the high reference result is taken when pipe is filled completely with oil. During a measurement capacitances between each pair of 12 electrodes are measured, giving rise to 66 measurements as an output. These data are collected by an acquisition unit and sent to a computer where a cross-section image is reconstructed and displayed using the colour codes for oil and gas. By the reconstructed image the phase distribution over the sensing cross sectional area at the measuring moment is obtained, and the liquid volume fraction in the pipe can further be estimated.

\subsection{Viscosity measurement and test condition}

Oil viscosities at different temperatures are measured by using a viscometer (Brookfield, LVDV-I, Prime). This viscometer is a type of the rotation variety which measure the torque required to rotate an immersed spindle in a fluid. The spindle is driven by a motor through a calibrated spring. The deflection of the spring is indicated by a pointer and a dial which are located above of the spring. For a given viscosity, the viscous drag is proportional to the spindle's rotation speed and is related to the spindle's geometry. Viscosity changes in a large range by changing the temperature in a water bath are measured by using a multiple speed transmission and interchangeable spindles. Results are shown in Figure 2, from which it can be seen that measured shear stress and shear rate at different viscosities are collated by a linear line, indicating the liquid used in this work with viscosity up to $9000 \mathrm{cP}$ is a Newtonian fluid. 


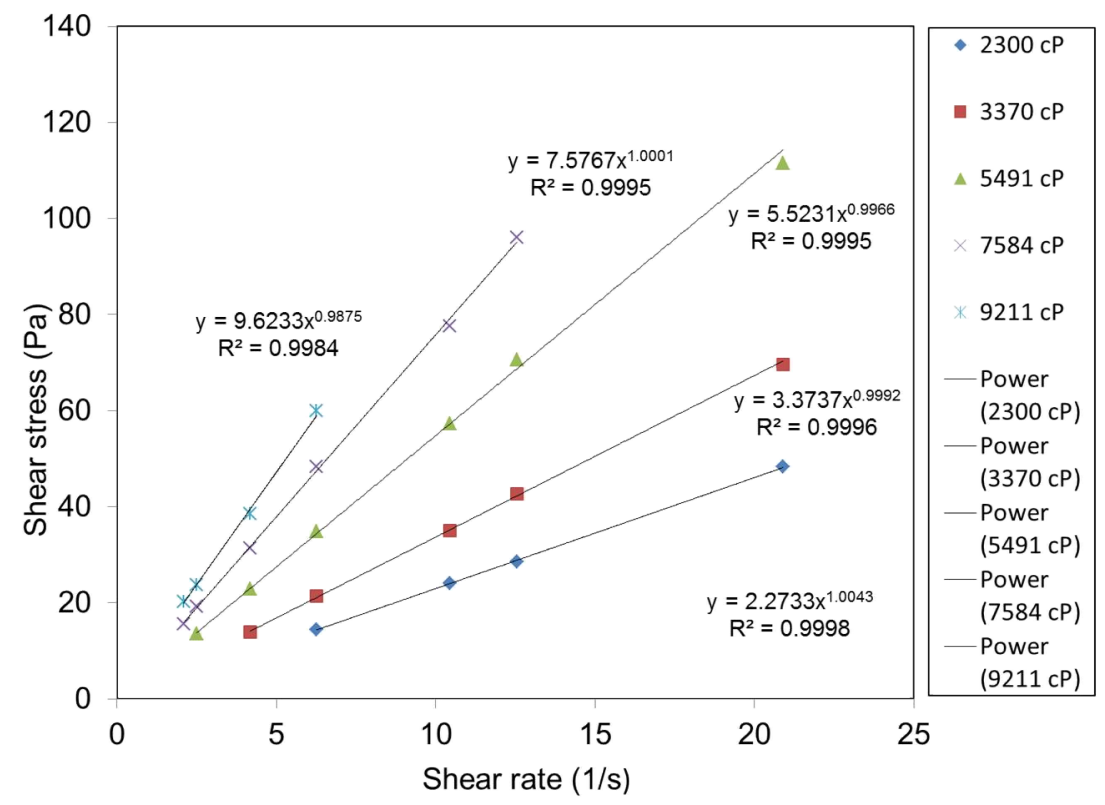

Figure 2 Power law model comparisons for different viscosities

The physical properties of the liquid and test conditions are listed in Table 1. The liquid viscosities used in experiments range from $919 \mathrm{cP}$ to $6226 \mathrm{cP}$. Liquid flow rate is controlled and varies from $0.06 \mathrm{~m} / \mathrm{s}$ to $0.2 \mathrm{~m} / \mathrm{s}$. The minimum and maximum velocities are limited by the rated pressure in the pipeline and the capacity of the pump. Gas flow is injected with a velocity range from $0.3 \mathrm{~m} / \mathrm{s}$ to $9 \mathrm{~m} / \mathrm{s}$. It might be noted that viscosity ranges, which are used to present results in the following sections, are taken from the minimum and the maximum values from one data set.

Table 1 Fluid properties and experiment conditions

\begin{tabular}{|c|c|c|c|c|c|c|}
\hline ID (m) & Test fluids & $\begin{array}{l}\text { Density } \\
\left(\mathrm{kg} / \mathrm{m}^{3}\right)\end{array}$ & Viscosity (cP) & $\begin{array}{c}\text { Interfacial } \\
\text { tension } \\
\left(25^{\circ} \mathrm{C}, \mathrm{N} / \mathrm{m}\right)\end{array}$ & $\begin{array}{c}\text { Test } \\
\text { matrix } \\
(\mathrm{m} / \mathrm{s})\end{array}$ & API gravity \\
\hline \multirow{3}{*}{0.074} & Air & 1.293 & 0.017 & \multirow{3}{*}{0.031} & $0.3-9.0$ & \multirow{3}{*}{22.67} \\
\hline & & & & & & \\
\hline & CYL680 & 918 & $919 \sim 6226$ & & $0.06-0.2$ & \\
\hline
\end{tabular}




\section{Experimental results and discussion}

\subsection{Flow patterns}

Flow patterns are observed to start with slug flow, which tends to dominate the entire flow regime. As gas velocity increases, rolling wave starts to occur at the film region. With further increasing gas velocity, oil phase is lifted by highly turbulent gas, and annular flow occurs with rolling wave at the interface. Snapshots for slug flow and annular flow obtained from videos and stacked images of ECT tomography are shown in Figure 3. A number of entrained gas bubbles are observed at the slug front. This could be attributed to scooping process in which the gas is entrapped in a mixing vortex resulted from a high kinetic energy in slug body (Dukler and Hubbard, 1975). However, the amount of gas entrainment in high viscosity liquid might be different from that in low viscosity liquid. Another apparent effect caused by high liquid viscosity is found at slug film region, where a thin oil film remains and drains along the pipe wall. The film behaves as ripple waves and moves with the gas core as a low velocity, resulting in high roughness at the interface between the top liquid film and gas core. It also can be seen in stacked images obtained from ECT. The

interface between gas core and bottom liquid film varies subsequently with slug bodies passing through. In annular flow, this interface is shaped as rolling waves and the mixing zone is particularly seen, indicating strong gas entrainments. Under strong gas shear forces, the top liquid film becomes thinner than that in slug flow. ECT visualizes fluctuations in the middle and a mixing zone at the top, representing the rolling wave at the interface and thin oil film attachment on the wall. 

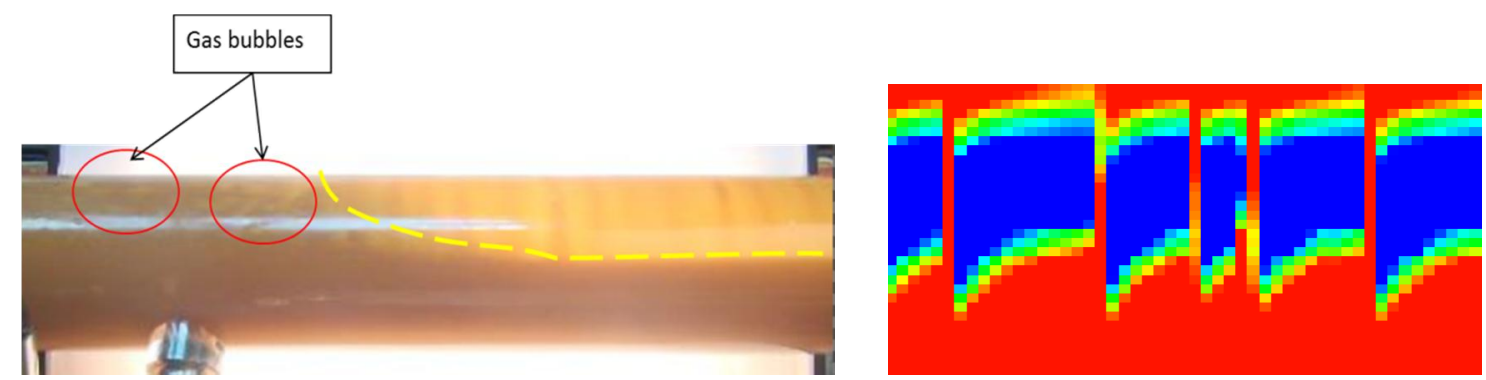

a. Slug flow
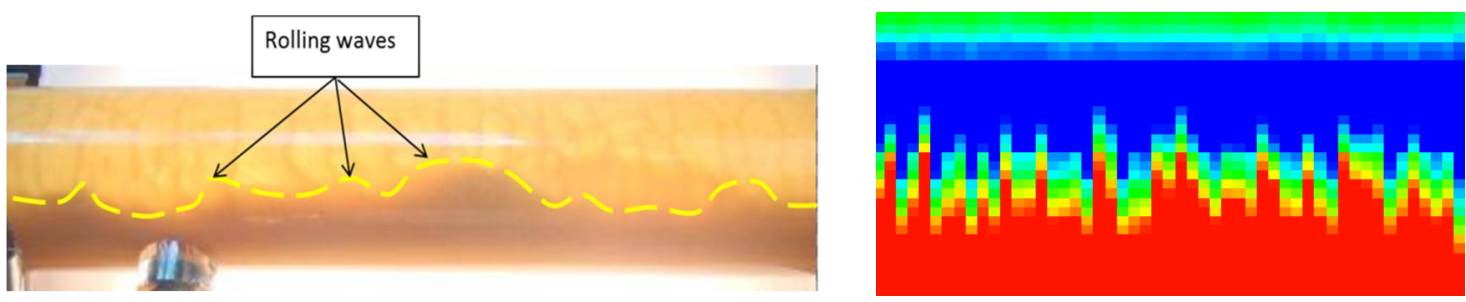

b. Annular flow

Figure 3 Flow patterns in 3-inch experiments obtained from videos and ECT tomography (side view, Red: oil, Blue: gas)

The comparison of flow regime map with regards to different oil viscosities is given in Figure 4. At oil viscosity range from $919 \mathrm{cP}$ to $1280 \mathrm{cP}$, slug flow occurs at the low gas velocity, and tends to sustain until gas velocity is around $1 \mathrm{~m} / \mathrm{s}$. Rolling waves with different amplitudes are observed at gas velocity of $2 \mathrm{~m} / \mathrm{s}$. When gas superficial velocity increases to $5 \mathrm{~m} / \mathrm{s}$, slug flow is replaced completely by annular flow. At liquid viscosity ranges from $3151 \mathrm{cP}$ to $3552 \mathrm{cP}$ and from $5845 \mathrm{cP}$ to $6226 \mathrm{cP}$, slug flow persists until gas superficial velocity is up to $2 \mathrm{~m} / \mathrm{s}$ and transitional features appear at gas superficial velocity of $3 \mathrm{~m} / \mathrm{s}$. Then, annular flow with ripples on the wall occurs at high superficial gas velocity. It is clear that as liquid viscosity increases, the area for slug flow in flow regime map is amplified. 

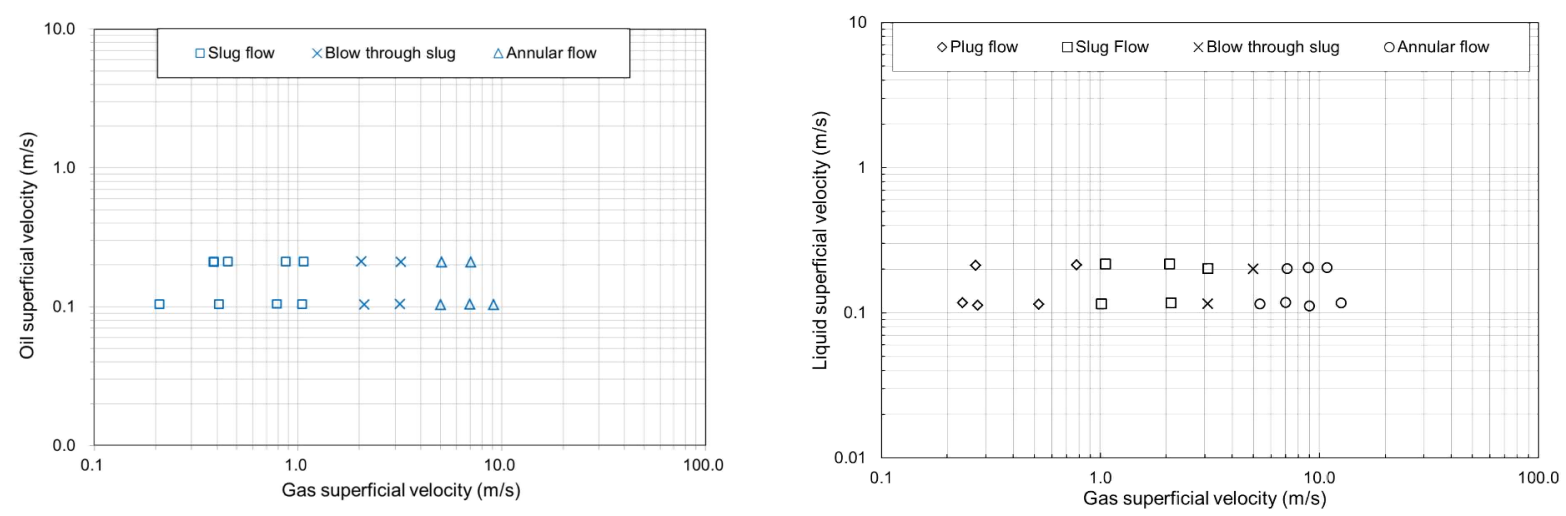

$919 \mathrm{cP}-1280 \mathrm{cP}$

$979 \mathrm{cP}-1183 \mathrm{cP}$

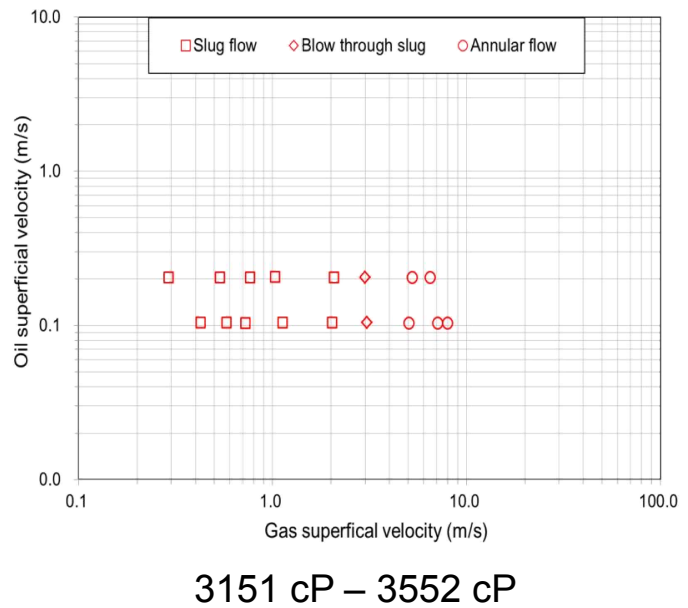

$0.074 \mathrm{~m}$ ID

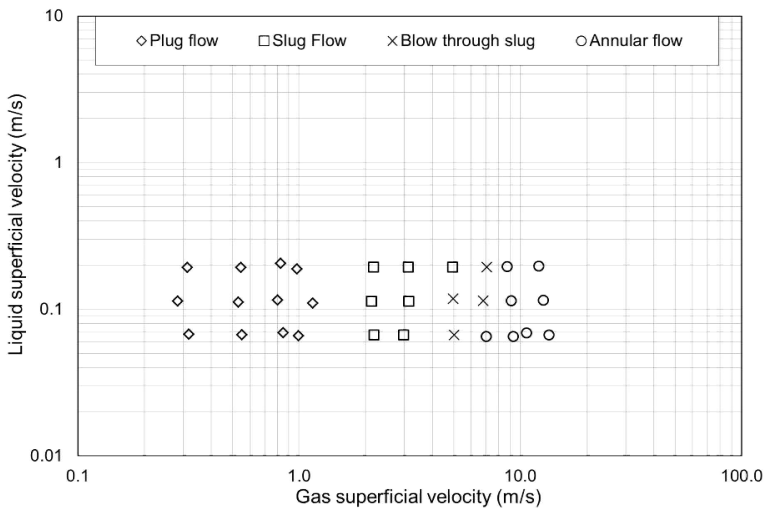

$3281 \mathrm{cP}-3665 \mathrm{cP}$

$0.026 \mathrm{~m}$ ID (Zhao et al. 2013a)

Figure 4 Flow regime map in experiments

The present flow regime map is compared to those obtained from Zhao et al. (2013a), in which viscous liquids and gas are tested in a $0.026 \mathrm{~m}$ ID and $5.5 \mathrm{~m}$ long horizontal pipe. Effects of pipe diameter on flow regime map are exhibited in Figure 4. At the similar liquid viscosity and velocity, the flow regime map for small diameter pipe tends to show more appearances of slug flow than that for large diameter pipe. In a small diameter pipe, slug flow is easily formed due to small pipe areas; while in a large diameter pipe with a higher ceiling, waves might need additional energy to develop into a slug. The mechanism responsible for the slug formation could be slightly different from that in a small diameter pipe. 
Since in high viscosity liquids, the critical gas superficial velocity which is required to cause unstable waves is still quite low, the transition from stratified flow to intermittent flow is not seen. But significant diameter effect is found on the transition from intermittent flow to annular flow. Annular flow in a large diameter pipe takes place at lower gas superficial velocity than that in a small diameter pipe, indicating that slug flow in small diameter pipe easily persist to large gas velocities. This tendency might be resulted from the mechanism of slug decay and transition to annular flow. In a small diameter pipe, it is expected that the unstable waves formed at the liquid-gas interface tend to bridge the pipe with less difficulty, and once slug body is formed slug flow maintains until gas flow containing high energy to penetrate through the slug body. But in a large diameter pipe, due to large available spaces, those unstable waves developing to slug need high gas energy and once the slug body is formed it might be difficult to maintain liquid body at such high gas superficial velocities.

\subsection{Liquid holdup}

Mean liquid holdup at the cross sectional area of the pipe is measured by ECT facility. The obtained time-series signals show an instantaneous volumetric fraction for liquid phase, and represent the characteristics for various flow patterns occurred in the pipe. Time-series data for slug flow regime is shown in Figure 5. It is seen that in slug flow, slug body and slug film are distinguished since the former has a large liquid content but a few of aerated gas bubbles; while the latter is characterized by a gas core and liquid film at the bottom. Slug units occur periodically as time increases and its mean liquid volume fraction $\left(E_{u}\right)$ is represented by the average time-series liquid holdups. A similar threshold $\left(E_{t h}\right)$, given in the equation below is adopted: 


$$
E_{t h}=\frac{1}{2}\left[\operatorname{Max}\left(E_{k}\right)+\operatorname{Min}\left(E_{k}\right)\right]
$$

Liquid holdup for slug body, $E_{s}$, can be determined by averaging those liquid holdups which are greater than $E_{t h}$; slug film has lower values of liquid holdup than $E_{t h}$ and the average of liquid holdup for film zone is defined as $E_{f}$. As gas superficial velocity increases, those peaks representing liquid volume fraction in slug body decreases and considerable fluctuations start to occur at the film region. As discussed above, at this flow pattern, slug body still passes but with a low frequency; while, large amplitude waves occur at film zone showing fluctuated trend. As increasing gas superficial velocity, slug body and slug film no longer occur and the average value of liquid holdup is obtained specifically for annular flow.

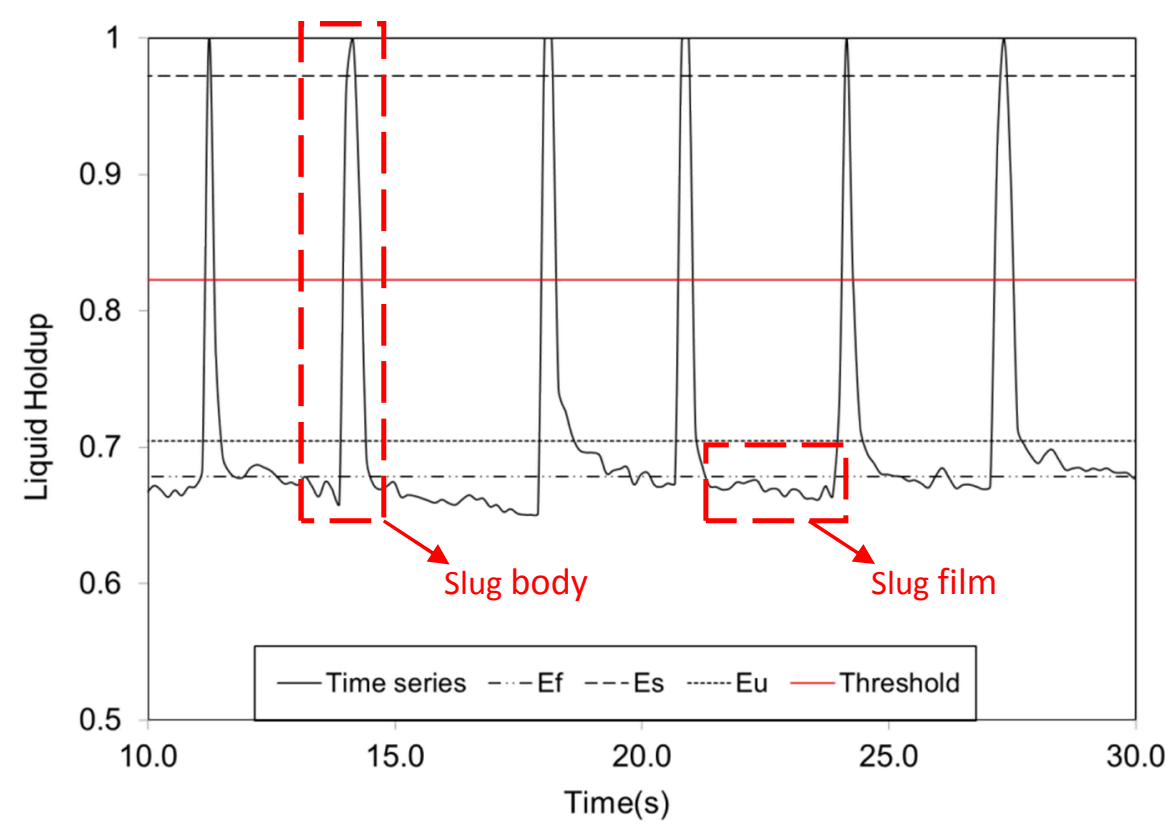

Figure 5 Time-series liquid holdup data (Slug flow at $U_{s o}=0.11 \mathrm{~m} / \mathrm{s}, U_{s g}=0.41 \mathrm{~m} / \mathrm{s}, 1204$ cP)

\subsubsection{Mean liquid holdup}

Liquid holdup in slug unit can be estimated by post-processing measured time-series liquid volume fraction. The experimental results in slug and annular flow are shown 
in Figure 6, in which it can be seen that the measured mean liquid holdup decreases as gas superficial velocity increases. This tendency seems gentle in slug flow but slightly sloping in annular flow. This indicates that increasing gas velocity only has a fairly limited effect on mean liquid holdup for both slug and annular flow. At low gas velocity, liquid flow tends to accumulate and gives a high liquid content in the pipe. Due to viscous nature, the liquid tends to attach on the pipe wall, which contributes a high value for the mean liquid holdup. With an increased gas superficial velocity, additional amount of gas result in the decrease in liquid holdup. As gas superficial velocity further increases, liquid phase no longer form liquid slugs in the pipe and annular flow occurs. The tendency of liquid holdup decreases continuously over the whole range of the gas superficial velocity. However, it is found that the entire decreasing trend is not so significant comparing with low viscosity liquid/gas flows. This indicates a large slip ratio and a rough interface.

On the other hand, mean liquid holdup in slug flow exhibits a little dependency on liquid viscosity and liquid velocity. In slug flow region, liquids with high viscosity and velocity tend to give a slightly higher liquid holdup. In annular flow region, this tendency is less obvious. The possible reason is attributed to the fact that the process of liquid deposition dominates in annular flow and is driven by turbulent gas energy, rather than viscous forces induced by liquid film. However, although the liquid volume fraction decreases with a relatively steep slope in slug region, it still travels and deposits on the top wall due to the adhesive property, leading to small reductions in overall liquid holdup in the whole gas velocity range. 


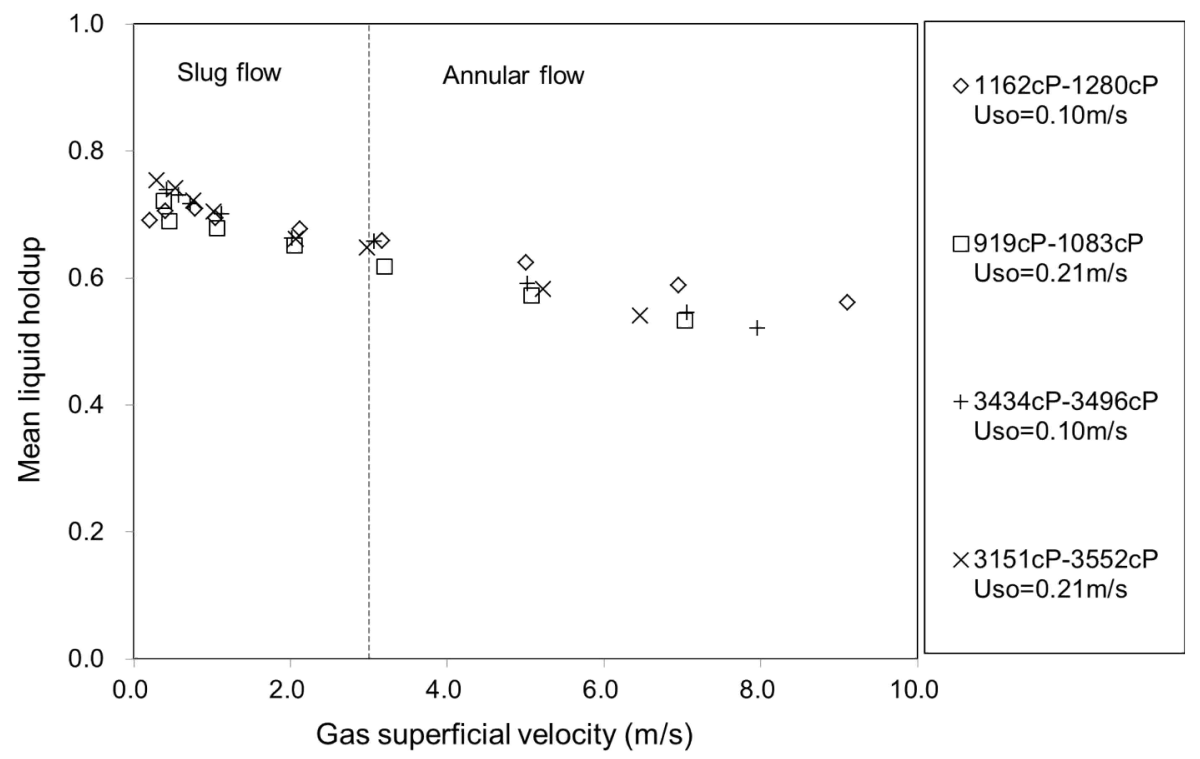

Figure 6 Liquid holdup in a slug unit in 3-inch experiments

\subsubsection{Slug body holdup}

Slug body holdups representing the gas aeration in slug body are sensitive to liquid viscosity. Slug body holdup results are shown in Figure 7 . It is seen that slug body holdup slightly decreases as mixture superficial velocity increases.

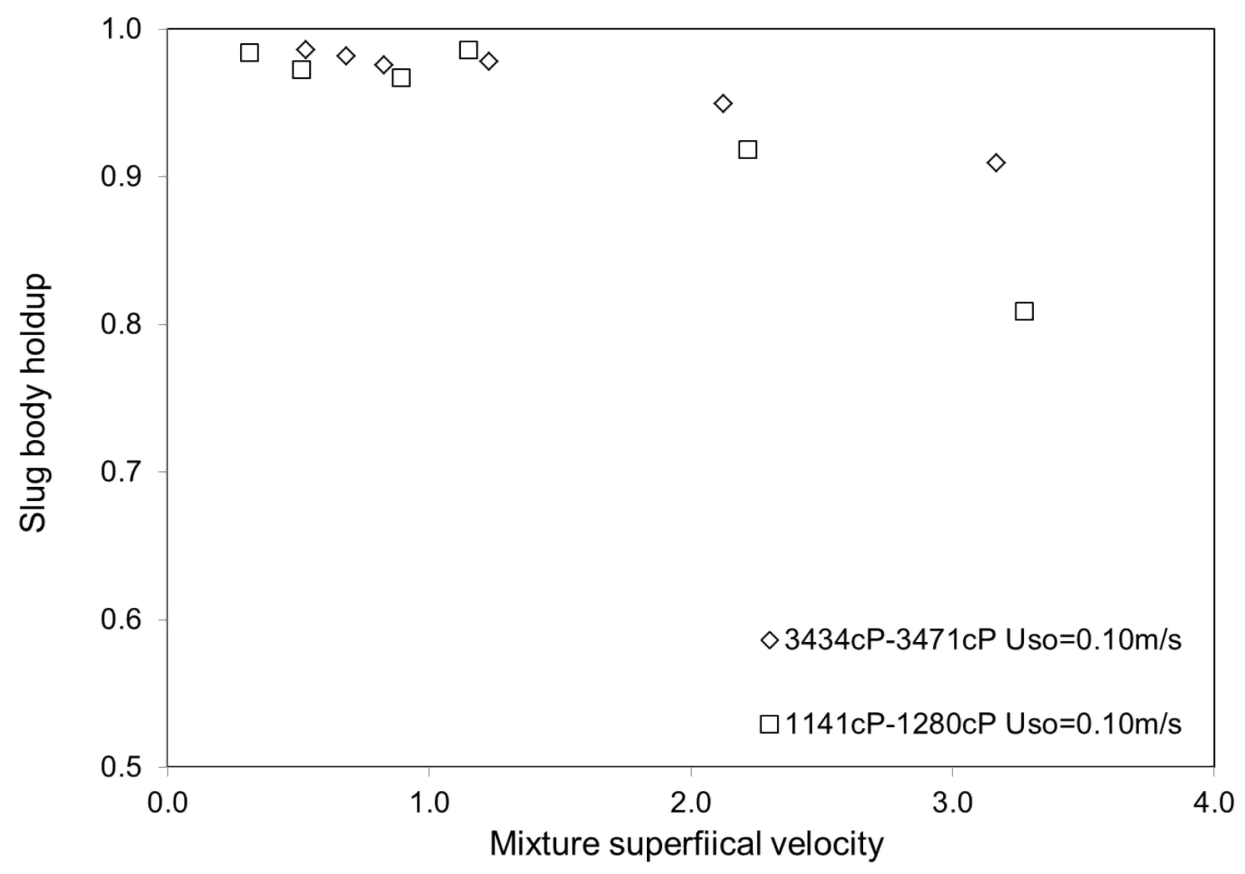

Figure 7 Slug body holdups in different liquid viscosities 
High viscosity liquids have high slug body holdups, indicating less gas aerations in viscous slug body. These effects are obvious when a critical velocity is reached. AlSafran et al. (2013) discussed liquid viscosity effects on slug body holdup and found that viscosity effects were significant when the mixture velocity was above a critical value. They found this critical velocity obtained from their tests using liquid with viscosity of $587 \mathrm{cP}$ was $2.0 \mathrm{~m} / \mathrm{s}$, and indicate it might become lower at higher liquid viscosity.

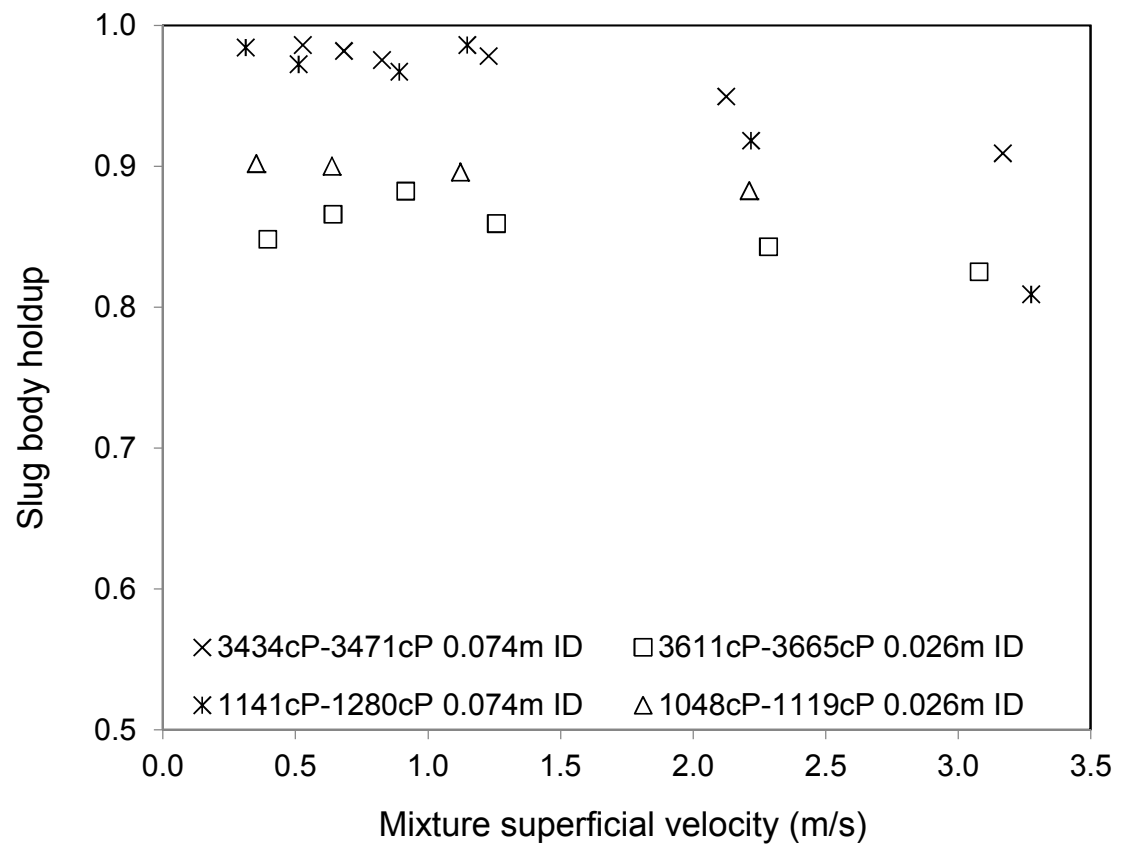

Figure 8 Slug body holdup comparison with $0.026 \mathrm{~m}$ ID experiments data from Zhao et al. (2013)

Liquid holdup data in slug body for both diameter pipes are shown in Figure 8. Significant effects of pipe diameter are represented by comparing results obtained from $0.074 \mathrm{~m}$ ID and $0.026 \mathrm{~m}$ ID pipes (Zhao et al., 2013a) for viscosities from around $1000 \mathrm{cP}$ to $3500 \mathrm{cP}$. It is found that at a similar viscosity range, slug body liquid holdup in the large diameter pipe is greater than that in the small diameter pipe, suggesting slug body in the small diameter pipe has more gas aerated. Since the scooping process explains the mechanism for gas entrained in slug body (Dukler 
and Hubbard, 1975), the turbulent kinetic energy is responsible for such phenomenon. However, Al-Safran et al., (2013) studied gas entrainment in viscous slug body and found that bubble fragmentation, occurred when turbulence kinetic energy overcomes the surface tension, is responsible for the dispersed gas bubble, as clearly seen in Figure 3.

Slug body holdup obtained are compared with predictions from Al-Safran et al. (2013), Kora et al. (2011), Abdul-Majeed (2000) and Gregory et al. (1978) and results are shown in Figure 9. The correlations of Gregory et al. (1978) were developed based on experiments using liquid viscosity of $6.75 \mathrm{cP}$. Kora et al. (2011) and AlSafran (2013) used liquids with viscosities up to $587 \mathrm{cP}$. The maximum liquid viscosity used in Abdul-Majeed (2000) was 7 cP. It is found that Kora et al. (2011) give a very close prediction to Al-Safran et al. (2013) for viscosity range around 1000 cP, and they both give a better prediction than Abdul-Majeed (2000) and Gregory et al. (1978). However, when liquid viscosity increases to around $3500 \mathrm{cP}$ scatters are found at high mixture superficial velocities (above $1.0 \mathrm{~m} / \mathrm{s}$ ). It might be expected as both models under predict the results when mixture velocity is higher than $1.5 \mathrm{~m} / \mathrm{s}$ and the viscosity starts to affect slug body holdup. 

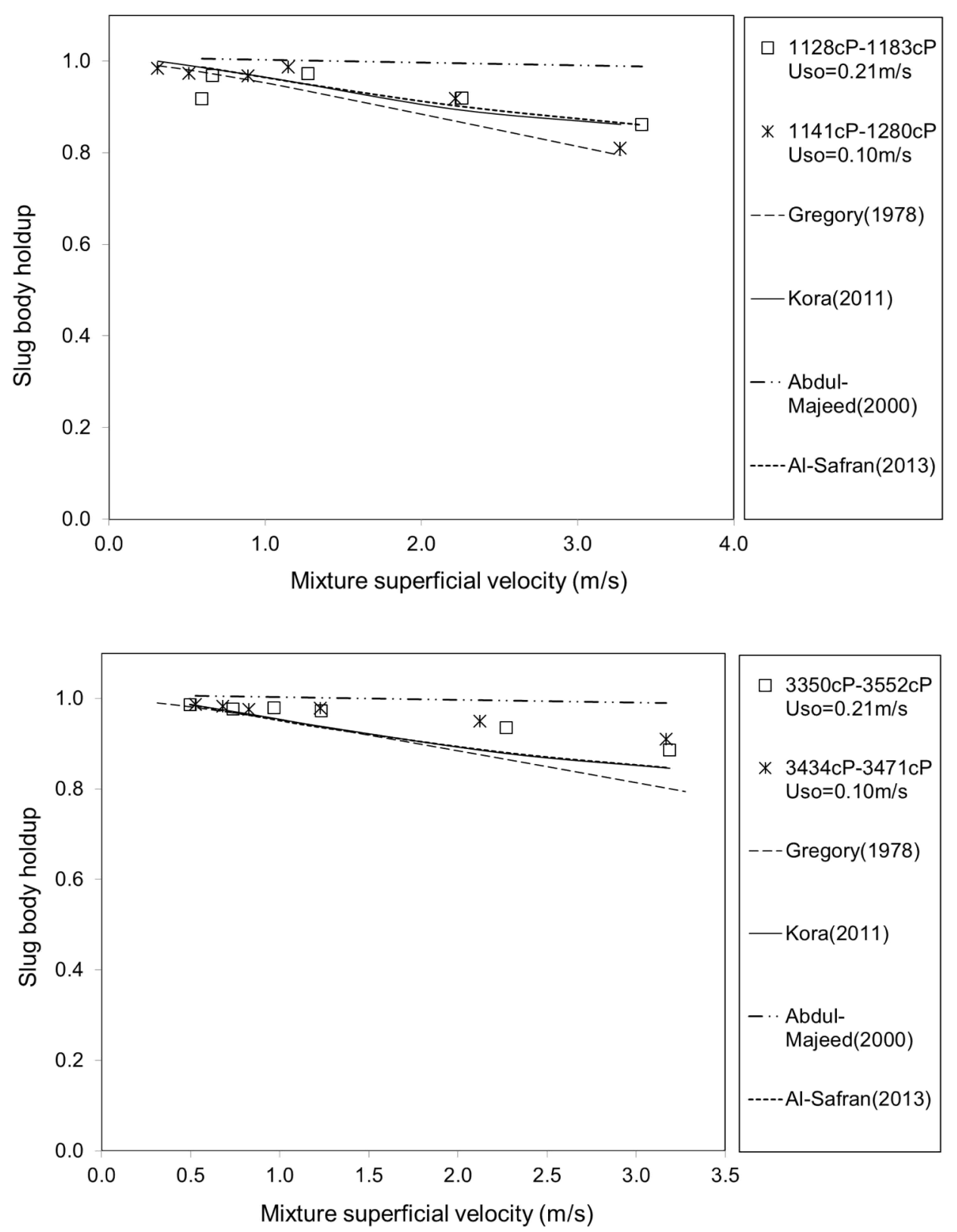

Figure 9 Slug body holdup from 3-inch experiments and comparison with correlations

\subsection{Pressure gradient}

In Figure 10, pressure gradient results obtained from experiments using around 1000 cP, $3500 \mathrm{cP}$ and $6000 \mathrm{cP}$ liquid viscosities are plotted against gas superficial velocities. For low liquid viscosity case with liquid superficial velocities of $0.10 \mathrm{~m} / \mathrm{s}$ and $0.21 \mathrm{~m} / \mathrm{s}$, pressure gradient increases steadily with increasing gas superficial velocity. This tendency is consistent with the trend in low viscosity liquid and gas flow 
(Gokcal et al., 2006; Foletti et al., 2011). When liquid viscosity increases to the range of around $3500 \mathrm{cP}$ and $6000 \mathrm{cP}$ at high liquid velocities, pressure gradient decreases at low gas superficial velocity and then increases with increasing gas superficial velocities.
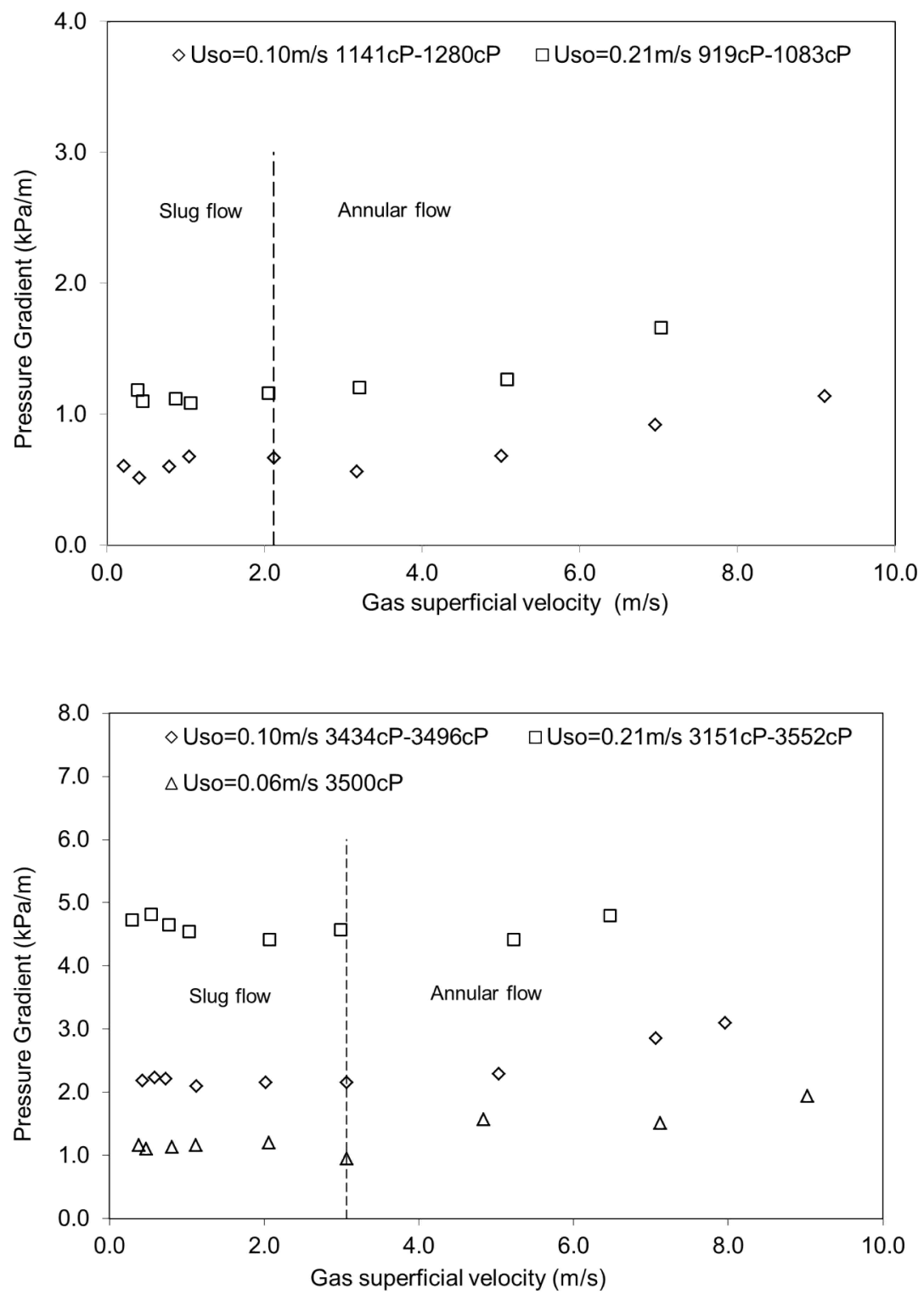


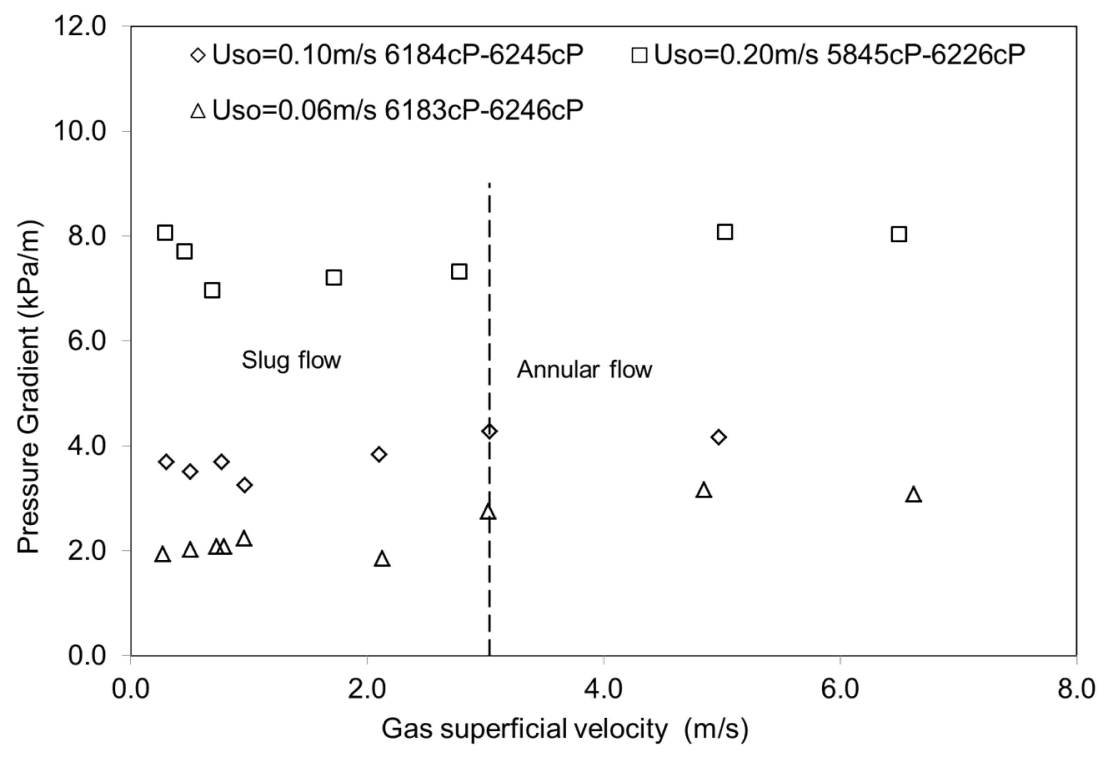

Figure 10 Pressure gradient in 3-inch experiments

It is found that variations of pressure gradient strongly depend on flow patterns. In slug flow, pressure gradient tends to persist as a stable trend. When flow becomes annular flow, pressure gradient increases as gas superficial velocity increases. This might be due to the fact that in annular flow, oil droplets are carried by turbulent gas flow and deposit at the top forming a thick oil layer. As a result, frictional pressure drops become significant. With further increasing gas superficial velocity, the oil layer becomes thicker and pressure gradient exhibits an increasing trend. 


\section{Model development}

\subsection{Continuity equations}

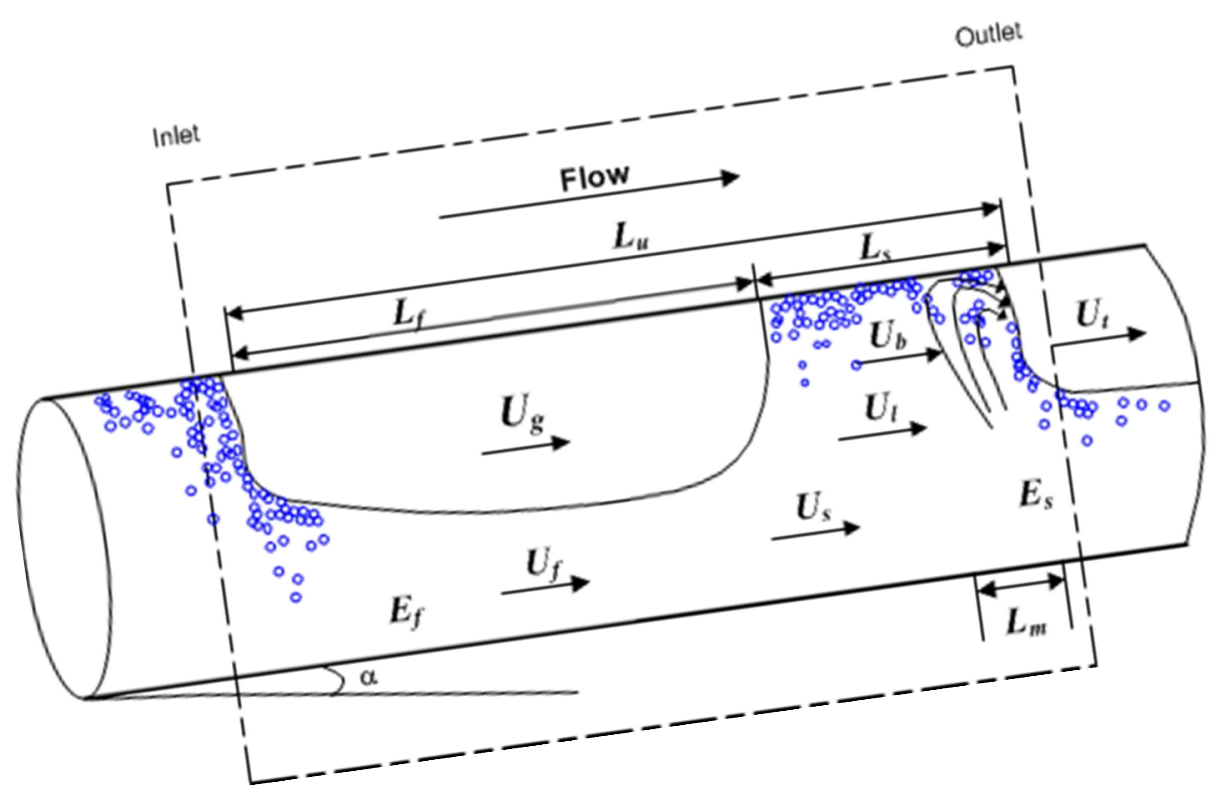

Figure 11 Slug flow geometry

The model described here is a steady-state two-fluid model and its derivation starts with assumptions that both liquid and gas flow are incompressible. This assumption applies even for long pipelines, where the density of gas phase is not constant, as suggested by Taitel and Barnea (1990). As shown in Figure 11, a slug unit consists of a liquid slug body with a length of $L_{s}$ and a film region with a length of $L_{f}$. The entrained gas bubble in slug body and gas pocket in film region are also presented. The continuity equation for liquid phase is written by balancing liquid mass flow rate at the inlet and outlet:

$$
E_{s}\left(U_{t}-U_{l}\right)=E_{f}\left(U_{t}-U_{f}\right)
$$

where, $E_{s}, E_{f}$ are liquid fraction in liquid slug and film region respectively. $U_{f}, U_{l}$ are liquid velocity in the film region and liquid slug. $U_{t}$ is the translational velocity at which slug unit propagates. 
The continuity equation for gas phase is

$$
\left(1-E_{s}\right)\left(U_{t}-U_{b}\right)=\left(1-E_{f}\right)\left(U_{t}-U_{g}\right)
$$

where $U_{g}$ is gas velocity in gas core and $U_{b}$ is the dispersed bubble velocity and Xiao, et al. (1990) and Wallis (1969) suggested $1.2 U_{s}\left(U_{s}\right.$ is the mixture superficial velocity) in horizontal pipes.

Summing Eq. (1) and (2) gives:

$$
U_{s}=E_{f} U_{f}+\left(1-E_{f}\right) U_{g}=E_{s} U_{l}+U_{b}\left(1-E_{s}\right)
$$

For a slug unit:

$$
\begin{gathered}
L_{u} U_{s l}=L_{s} E_{s} U_{s}+L_{f} E_{f} U_{f} \\
L_{u} U_{s g}=L_{s}\left(1-E_{s}\right) U_{s}+L_{f}\left(1-E_{f}\right) U_{g} \\
L_{u}=L_{s}+L_{f}
\end{gathered}
$$

where, $L_{u}, L_{s}, L_{f}$ are the length of slug unit, slug body and slug film respectively. These equations yield several important relationships, one of which is the mean liquid holdup for a slug unit:

$$
E_{u}=\frac{U_{t} E_{s}+U_{b}\left(1-E_{s}\right)-U_{s g}}{U_{t}}
$$

\subsection{Momentum equations}

Momentum balance is also applied to the slug unit. Momentum equations are based on the analysis of forces exerted at the both side of the slug structure and are used 
to solve pressure drop and other flow characteristics. Zhang et al. (2003a) considered the entire liquid film in a slug unit as a control volume, and derived momentum equations based on momentum input and output at the left and right boundary of the film, respectively. If a constant liquid height is assumed, the momentum equations for liquid film and gas core are given as:

$$
\begin{aligned}
& \frac{\rho_{l}\left(U_{t}-U_{f}\right)\left(U_{l}-U_{f}\right)}{L_{f}}=\frac{\Delta P}{L_{f}}+\frac{\tau_{f} S_{f}}{A_{f}}-\frac{\tau_{i} S_{i}}{A_{f}}+\rho_{l} g \sin \alpha \\
& \frac{\rho_{g}\left(U_{t}-U_{g}\right)\left(U_{b}-U_{g}\right)}{L_{f}}=\frac{\Delta P}{L_{f}}+\frac{\tau_{g} S_{g}}{A_{g}}+\frac{\tau_{i} S_{i}}{A_{g}}+\rho_{g} g \sin \alpha
\end{aligned}
$$

If pressure term is eliminated, the combined momentum equation is given as:

$$
M-\frac{\tau_{f} S_{f}}{A_{f}}+\frac{\tau_{g} S_{g}}{A_{g}}+\tau_{i} S_{i}\left(\frac{1}{A_{f}}+\frac{1}{A_{g}}\right)-\left(\rho_{l}-\rho_{g}\right) g \sin \alpha=0
$$

where,

$$
M=\frac{\rho_{l}\left(U_{t}-U_{f}\right)\left(U_{l}-U_{f}\right)-\rho_{g}\left(U_{t}-U_{g}\right)\left(U_{b}-U_{g}\right)}{L_{f}}
$$

$M$, represents momentum exchanges between slug body and film region. In stratified flow or annular flow, $L_{f}$ tends to be infinitely long and hence $M$ is negligible. In viscous liquid and gas flow, there is a high liquid film height (Nädler and Mewes, 1995 and Zhao et al., 2013b), resulting in a low liquid velocity in slug film zone and a high gas velocity in gas pocket. In this case, the momentum exchange term becomes significant. Additionally, reported characteristics of high slug frequency and short length in viscous liquids may result in short film length and, therefore, a high 
value of $M$. It is noted that high shear stresses on the liquid film induced by high gas velocity may cause complicated liquid droplet entrainments in gas pocket and the changes of wave characteristics at the interface. The liquid droplet may travel with gas core and deposit at the wall where a ripple wave is formed. Since this mechanism is not yet discovered, only a few amount of liquid droplet is assumed in gas pocket zone in this study.

In above equations, $\tau_{f}, \tau_{g}, \tau_{i}$ are liquid-wall, gas-wall and interfacial shear stress, respectively. They are defined as:

$$
\begin{gathered}
\tau_{f}=f_{l} \frac{\rho_{l} U_{l}^{2}}{2} \\
\tau_{g}=f_{g} \frac{\rho_{g} U_{g}{ }^{2}}{2} \\
\tau_{i}=f_{i} \frac{\rho_{g}\left(U_{g}-U_{f}\right)\left|U_{g}-U_{f}\right|}{2}
\end{gathered}
$$

Geometrical parameters, $A_{f}, A_{g}, S_{f}, S_{g}, S_{i}, E_{f}$, are functions of liquid film height $h_{f} / D:$

$$
\begin{gathered}
A_{f}=E_{f} A \\
A_{g}=\left(1-E_{f}\right) A \\
S_{f}=D\left\{\pi-\cos ^{-1}\left[2\left(h_{f} / D\right)-1\right]\right\} \\
S_{g}=D \cos ^{-1}\left[2\left(h_{f} / D\right)-1\right]
\end{gathered}
$$




$$
\begin{gathered}
S_{i}=D \sqrt{1-\left[2\left(h_{f} / D\right)-1\right]^{2}} \\
E_{f}=(1 / \pi)\left\{\pi-\cos ^{-1}\left[2\left(h_{f} / D\right)-1\right]+\left[2\left(h_{f} / D-1\right] \sqrt{1-\left[2\left(h_{f} / D\right)-1\right]^{2}}\right\}\right.
\end{gathered}
$$

Note that a flat interface is assumed here. The Reynolds numbers for liquid film and gas core are defined as:

$$
\begin{gathered}
\operatorname{Re}_{f}=\frac{4 A_{f} U_{f} \rho_{l}}{S_{f} \mu_{l}} \\
\operatorname{Re}_{g}=\frac{4 A_{g} U_{g} \rho_{g}}{\left(S_{g}+S_{i}\right) \mu_{g}}
\end{gathered}
$$

Taitel and Dukler (1976) suggested that the chord length at the interface, $S_{i}$, is considered in gas Reynolds number. It might still be applied in viscous liquid and gas flow. The reason could be that gas phase has a higher velocity than liquid, and interfacial shear stress still has a same direction with gas-wall shear stress.

Pressure drop for an entire slug unit, $\Delta P_{u}$, is the sum of the pressure drop of slug film, and slug body. The pressure gradient in the film zone for a horizontal pipe is calculated as:

$$
\left(\frac{d P}{d z}\right)_{f}=\frac{\rho_{l} E_{f}\left(U_{t}-U_{f}\right)\left(U_{l}-U_{f}\right)}{L_{f}}+\frac{\rho_{g} E_{s}\left(U_{t}-U_{g}\right)\left(U_{b}-U_{g}\right)}{L_{f}}-\frac{\tau_{f} S_{f}}{A}-\frac{\tau_{g} S_{g}}{A}
$$

The pressure gradient in the slug body is

$$
\left(\frac{d P}{d z}\right)_{s}=-\frac{\rho_{l} E_{f}\left(U_{t}-U_{f}\right)\left(U_{l}-U_{f}\right)}{L_{s}}-\frac{\rho_{g} E_{s}\left(U_{t}-U_{g}\right)\left(U_{b}-U_{g}\right)}{L_{s}}-\frac{\tau_{s} \pi D}{A}
$$

The pressure gradient for a slug unit is: 


$$
\left(\frac{d P}{d z}\right)_{u}=-\frac{\tau_{s} \pi D}{A} \frac{L_{s}}{L_{u}}-\frac{\tau_{f} S_{f}+\tau_{g} S_{g}}{A} \frac{L_{f}}{L_{u}}
$$

The shear stress in the slug body, $\tau_{s}$, is given as:

$$
\tau_{s}=f_{s} \frac{\rho_{s} U_{s}^{2}}{2}
$$

where, $f_{s}$ is calculated using mixture properties in slug body, $\rho_{s}$ and $\mu_{s}$, which are given as:

$$
\begin{aligned}
& \rho_{s}=E_{s} \rho_{l}+\left(1-E_{s}\right) \rho_{g} \\
& \mu_{s}=E_{s} \mu_{l}+\left(1-E_{s}\right) \mu_{g}
\end{aligned}
$$

$E_{s}$ is liquid holdup in slug body.

\subsection{Closure equations}

\subsubsection{Translational velocity}

Slug translational velocity, $U_{t}$, is represented as a function of mixture velocity, $U_{s}$, and drift velocity, $U_{d}$, in the form proposed by Nicklin (1962).

$$
U_{t}=C U_{s}+U_{d}
$$

where, $C$ is a coefficient which refers to the ratio of maximum to the mean velocity for a fully developed velocity profile. Nicklin proposed a value of 1.2 for $C$ when flow is turbulent, and a value of 2 when flow is laminar. $U_{d}$ is the drift velocity which represents bubble motion in a stagnant liquid. Bendiksen (1984) gave a correlation for drift velocity at the horizontal and upward inclined pipe flow, which is widely used as: 


$$
U_{d}=0.54 \sqrt{g D} \cos \alpha+0.35 \sqrt{g D} \sin \alpha
$$

Liquid viscosity effects on drift velocity was investigated by Gokcal et al.(2009a) for liquid viscosities ranging from $1 \mathrm{cP}$ to $1237 \mathrm{cP}$. Experimental results showed a decreasing tendency in drift velocity with increasing liquid viscosity. Jeyachandra et al. (2010) extended Gokcal's works for different pipe diameter and liquid viscosity by developing a simple model for drift velocity in horizontal pipes:

$$
F r=0.53 e^{-13.7 N_{\mu}^{0.46} E_{o}^{-0.1}}
$$

where, $\mathrm{Fr}, N_{\mu}$ and $E_{o}$ are dimensionless parameters:

$$
F r=\frac{U_{d}}{\sqrt{g D}} \quad N_{\mu}=\frac{\mu_{l}}{\rho_{l} D^{1.5} g^{0.5}} \quad E_{o}=\frac{\rho_{l} D^{2} g}{\sigma_{l}}
$$

Although this correlation was developed based on experimental results for a limited liquid viscosity range, it is tested against high viscosity results.

\subsubsection{Slug liquid holdup}

In Figure 12, the present experimental results and those obtained from Zhao et al. (2013a) for $0.026 \mathrm{~m}$ ID pipe are compared with predictions from available correlations. Statistically analysis for the performance of these correlations using six evaluation parameters (equations are listed in Appendix 1) is given in Table 1. 


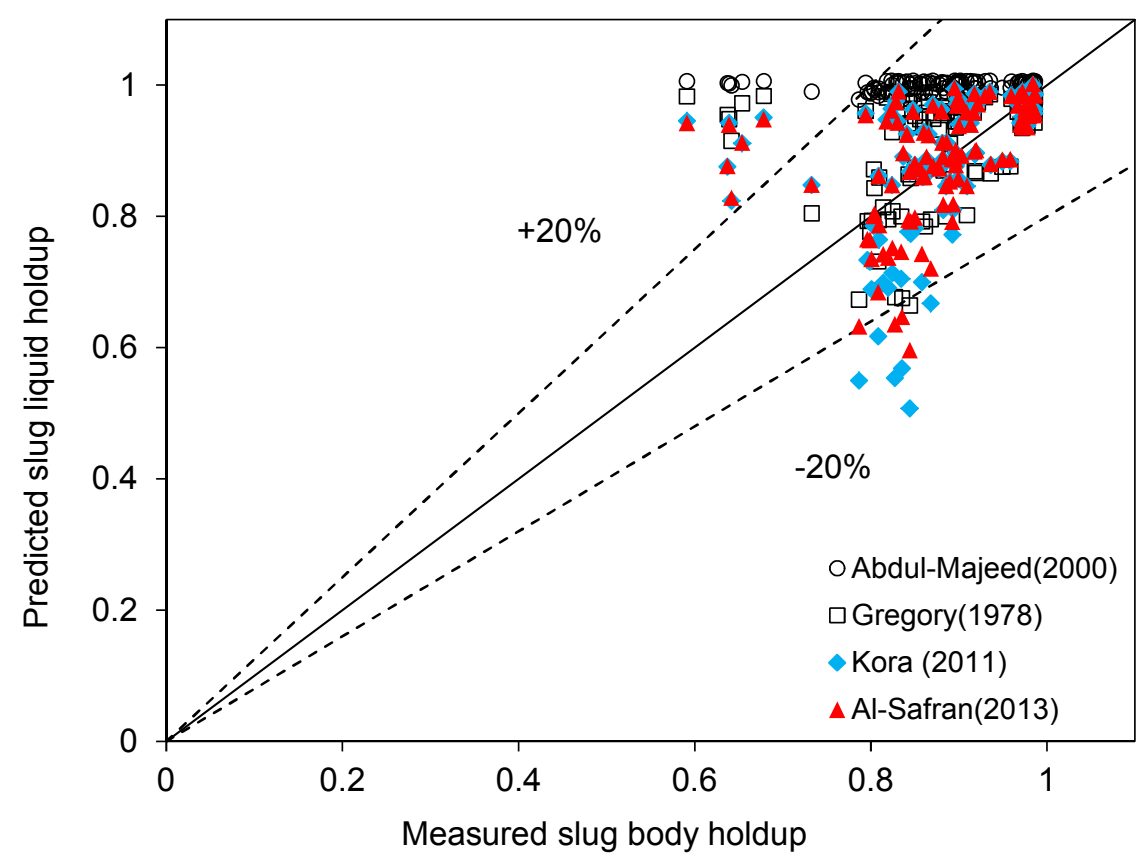

Figure 12 Comparison of slug liquid holdup between the present results and results from Zhao et al. (2013) and predictions from correlations

Table 1 Comparison of measured liquid holdups (Zhao et al. 2013) and prediction from correlations

\begin{tabular}{|c|c|c|c|c|c|c|}
\hline \multirow{2}{*}{ Correlations } & \multicolumn{6}{|c|}{ Statistical Parameters (\%) } \\
\cline { 2 - 7 } & $\varepsilon 1$ & $\varepsilon 2$ & $\varepsilon 3$ & $\varepsilon 4$ & $\varepsilon 5$ & $\varepsilon 6$ \\
\hline $\begin{array}{c}\text { Al-Safran et } \\
\text { al.(2013) }\end{array}$ & 2.36 & 6.96 & 13.60 & 1.44 & 6.96 & 9.89 \\
\hline \begin{tabular}{c} 
Kora et al.(2011) \\
\hline $\begin{array}{c}\text { Gregory et } \\
\text { al.(1978) }\end{array}$
\end{tabular} & 1.24 & 9.93 & 15.20 & 0.52 & 7.91 & 11.33 \\
\hline $\begin{array}{c}\text { Abdul- } \\
\text { Majeed(2000) }\end{array}$ & 16.09 & 16.09 & 12.69 & 12.98 & 12.98 & 8.10 \\
\hline
\end{tabular}

It can be seen that Al-Safran et al. (2013) and Kora et al. (2011) give the closest predictions. The reason is that their correlations were developed considering liquid viscosity effects and experiments were conducted by using liquids with relative high viscosity. The correlation of Gregory et al.(1978), which is proved to have a widely application in low viscosity liquid cases (Pereyra et al., 2012; Al-Safran et al., 2013), 
gives slightly greater errors in the predictions of slug holdup at liquid viscosity above 1000 cP. Therefore, the correlation of Al-Safran et al. (2013)

$$
\begin{gathered}
E_{s}=0.85-0.075 \varphi+0.057 \sqrt{\varphi^{2}+2.27} \\
\varphi=N_{F r} N_{\mu}{ }^{0.2}-0.89
\end{gathered}
$$

is used in the model developed in this study.

\subsubsection{Slug body length}

Experimental observations for air and water slug flow in the horizontal pipe suggest that a stable slug length is independent of gas and liquid flow rate and fairly constant for pipe diameter (Taitel and Barnea, 1990). Slug liquid body length in air and water flow has an average value of 12-30D (Dukler and Hubbard, 1975). Al-Safran et al. (2011) studied experimentally the effect of liquid viscosity on slug body length in horizontal gas-liquid flow. Higher frequency and shorter slug length with increasing oil viscosity were observed and explained by theoretical and physical reasoning. A new correlation to predict slug body length with a consideration of liquid viscosity was proposed:

$$
\frac{L_{s}}{D}=2.63\left(\frac{D^{3 / 2} \sqrt{\rho_{l}\left(\rho_{l}-\rho_{g}\right) g}}{\mu_{l}}\right)^{0.321}
$$

This correlation is used in the model developed in this paper.

\subsubsection{Two-phase friction factor}

Liquid-wall and gas-wall shear stress in two-phase flow have also been investigated (Taitel and Dukler, 1976; Newton, et al. 1999; Kowalski, 1987). No obvious dependence of the gas/wall shear stress on interfacial conditions or liquid properties 
was found. Gas/wall friction factor in two-phase flow can be estimated by the following equations, as described in Taital and Dukler (1976):

$$
\begin{array}{ll}
f_{g}=16 \operatorname{Re}_{g}^{-1} & \text { for } \operatorname{Re}_{g} \leq 2100 \\
f_{g}=0.046 \operatorname{Re}_{g}^{-0.2} & \text { for } \operatorname{Re}_{g}>2100
\end{array}
$$

Zhao et al. (2013b) proposed a new correlation for the friction factor for laminar liquid and pipe wall in gas and liquid two phase flow, based on experimental results for a large range of liquid viscosity.

$$
f_{l}=20.76 \operatorname{Re}_{l}^{-1} \quad \text { for } \operatorname{Re}_{l} \leq 2100
$$

For turbulent liquid and wall, the friction factor is determined by Kowalski (1987), in which wall-to-liquid shear was measured and data was used to fit a correlation in terms of in-situ liquid holdup, $E_{f}$, and superficial Reynolds number, $\mathrm{Re}_{s l}$.

$$
f_{l}=0.0262\left(E_{f} \mathrm{Re}_{s l}\right)^{-0.139} \quad \text { for } \operatorname{Re}_{l}>2100
$$

Interfacial friction factor is a critical parameter associated with interfacial characteristic in gas and liquid flows. Andritsos and Hanratty (1987b) expressed different correlations for smooth and rough interface due to appearance of large amplitude waves:

$$
\begin{array}{cc}
\frac{f_{i}}{f_{g}}=1 & \text { for } U_{s g} \leq U_{s g, t} \\
\frac{f_{i}}{f_{g}}=1+15\left(\frac{h_{f}}{D}\right)^{0.5}\left(\frac{U_{s g}}{U_{s g, t}}-1\right) & \text { for } U_{s g}>U_{s g, t}
\end{array}
$$


$\frac{h_{f}}{D}$ is the non-dimension liquid film height. $U_{s g, t}$ is the critical gas superficial velocity at which large amplitude waves appear. For water and gas flow, the critical velocity is defined in Andritsos and Hanratty (1987b):

$$
U_{s g, t, w}=5\left(\frac{\rho_{g o}}{\rho_{g}}\right)^{0.5}
$$

where $\rho_{g o}$ is the gas density at atmospheric pressure. In viscous liquid and gas flow, it was found that the onset of large amplitude wave motion on the gas-liquid interface happened at a low gas superficial velocity (Newton et al., 1999; Matsubara et al., 2011). Another instability investigation carried out by Andritsos and Hanratty (1987a) also revealed that the ratio of the critical gas superficial velocity for water and any liquid was a function of liquid height and viscosity. Zhao et al. (2013b) considered viscosity effects on the critical gas superficial velocity and proposed a correlation for interfacial friction factor:

$$
\frac{f_{i}}{f_{g}}=1+15\left(\frac{h_{f}}{D}\right)^{0.5}\left[\frac{U_{s g}}{U_{s g, t, w}}\left(\frac{\mu_{l}}{\mu_{w}}\right)^{0.99}-1\right]
$$

\section{Model validation}

The mechanistic model is developed for the prediction of pressure gradient and liquid holdup in a dominant slug flow region for viscous liquid and gas flow in a horizontal pipe. A calculation procedure is given in Appendix 1. The model requires inputs of fluid properties, superficial velocities and pipe diameter and assumes an initial value for liquid height. Then from continuity equations, velocities in slug body and film zone are calculated. To solve the momentum equation in the film zone, correlations of friction factors for gas-wall, liquid-wall and interface are employed. As 
a solution of the combined momentum equation, a new liquid height is evaluated and compared with the old value until the relative error is below 0.0001 . The pressure and mean liquid holdup over the entire slug unit are then calculated. Model performance is evaluated by comparing experimental results of water and gas and viscous liquid and gas system.

\subsection{Pressure gradient predictions}

Two sets of water/gas experimental data are used to compare with model predictions. One is sourced from Andritsos (1986) who performed experiments in a horizontal pipe with a diameter of $0.025 \mathrm{~m}$; the other is from internal data tested in a $0.026 \mathrm{~m}$ ID and $5.5 \mathrm{~m}$ long horizontal pipe in Cranfield University (Zorgani, et al., 2012). As seen in Figure 13, measured pressure gradient are well predicted by the derived model within an error of $\pm 20 \%$.

Further validations are carried out by comparing the present results, results obtained by Gokcal (2005). The latter performed experiments in a $0.0508 \mathrm{~m}$ ID horizontal pipe with liquid viscosities ranged from $180 \mathrm{cP}$ to $589 \mathrm{cP}$. As shown in Figure 14, predictions from the mechanistic model agreed well with Gokcal's results in the entire range of liquid viscosities. Errors are found to be within $\pm 30 \%$. These good agreements show promising performance of the model for pressure gradient not only for water and gas flows $(1 \mathrm{cP})$, but also for other liquid flow with large range of viscosities (180 cP-589 cP). The comparison of pressure gradient calculated from the model and obtained from the present experiment, which results cover a liquid viscosity range from $1000 \mathrm{cP}$ to $7500 \mathrm{cP}$, is shown in Figure 5 . A good agreement is found and the model is proved to be applicable when liquid viscosity is within a much higher range (1000 cP-6000 cP). 


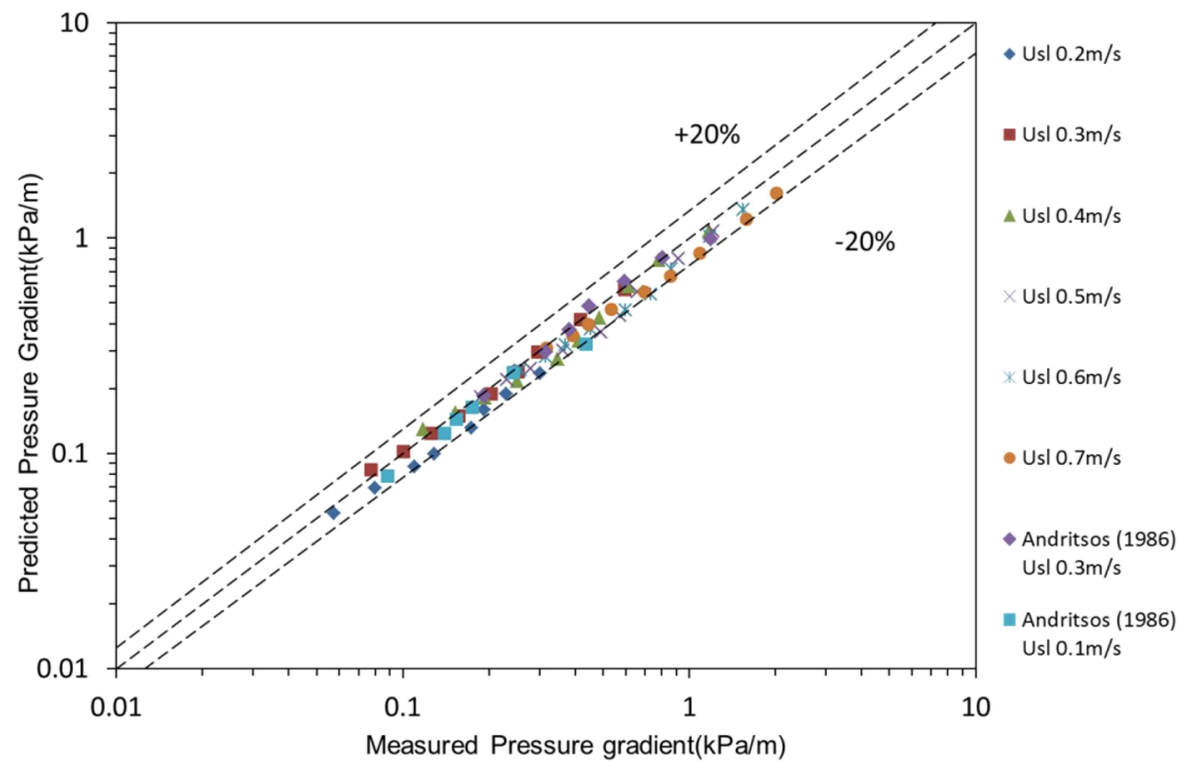

Figure 13 Comparison of pressure gradient of water and gas flows from Andritsos (1986) and experimental measurements

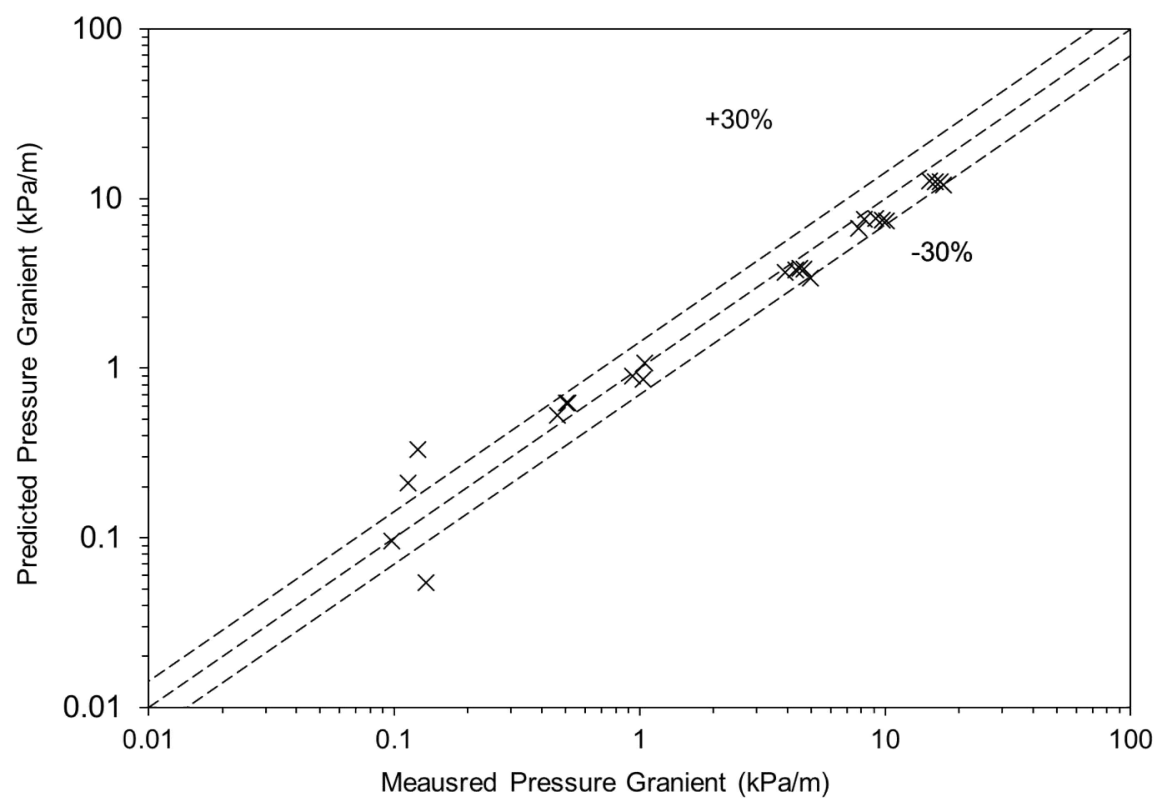

a. $587 \mathrm{cP}$ 


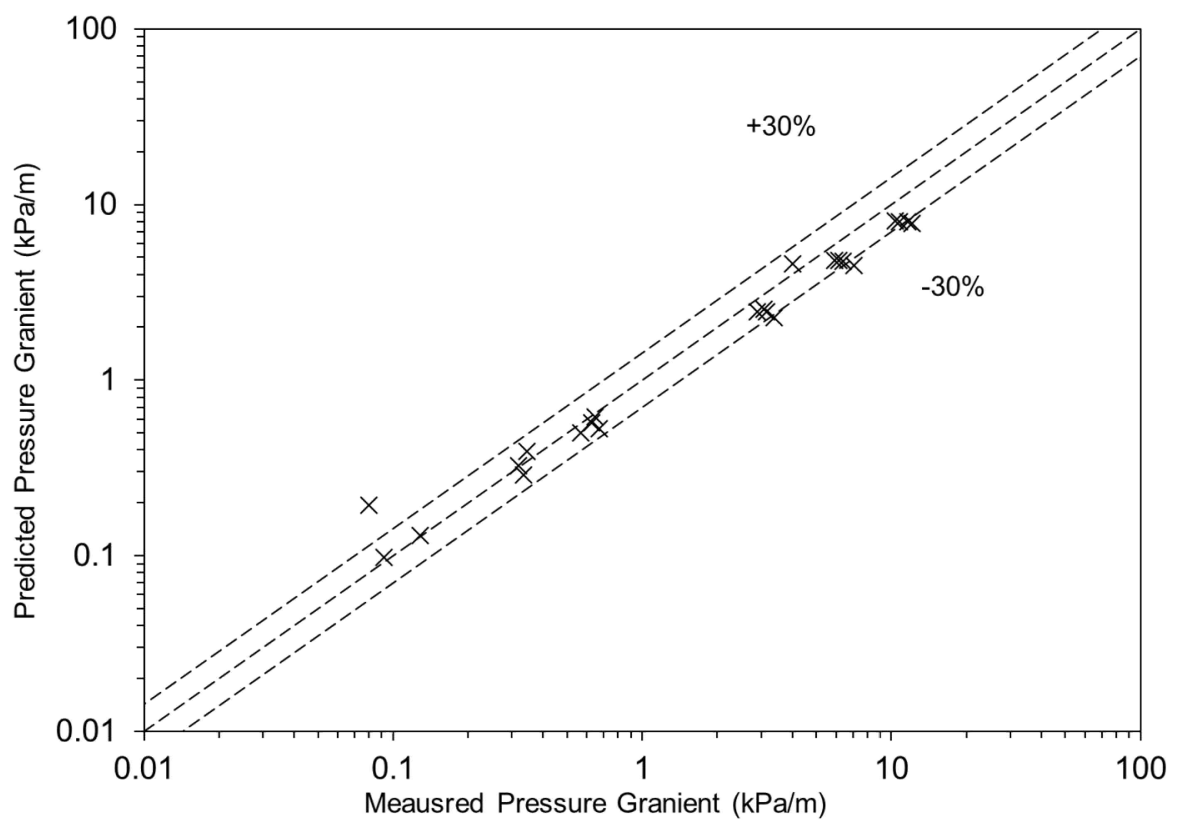

b. $387 \mathrm{cP}$

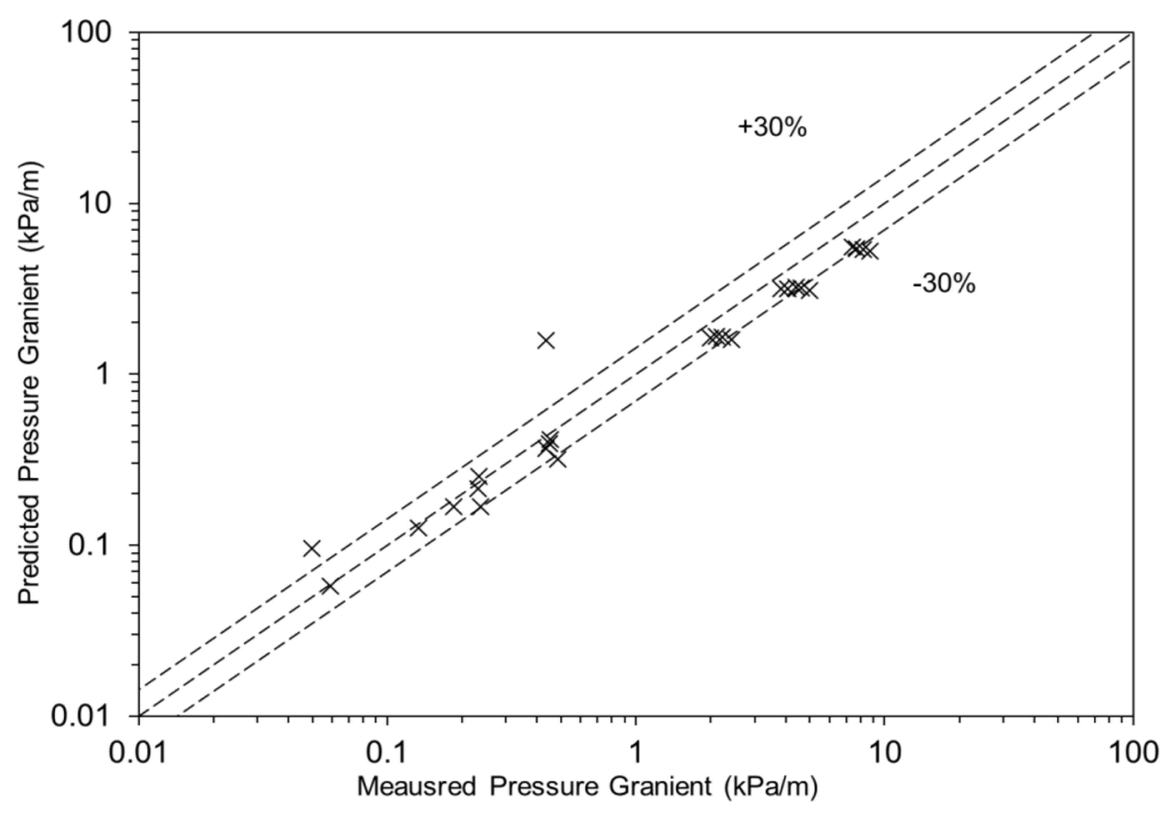

C. $250 \mathrm{cP}$ 


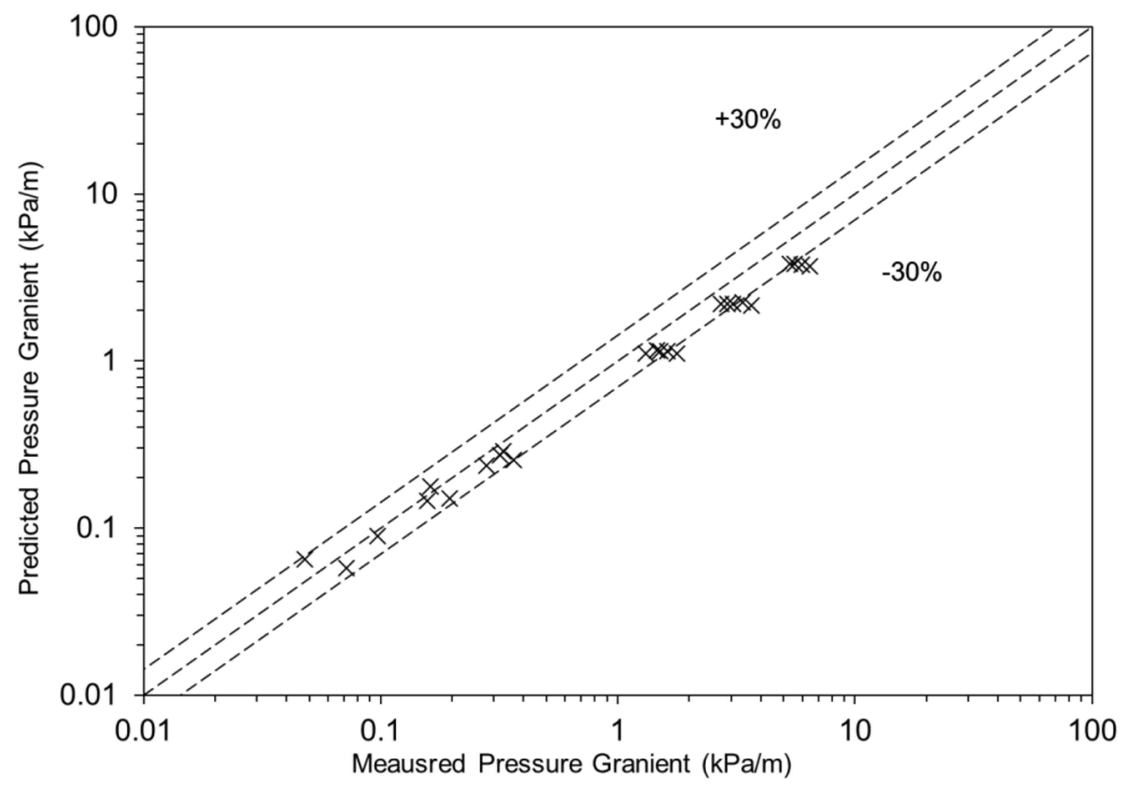

d. $180 \mathrm{cP}$

Figure 14 Pressure comparison between prediction and Gokcal et al.(2005) data with viscosities from $587 \mathrm{cP}$ to $180 \mathrm{cP}$

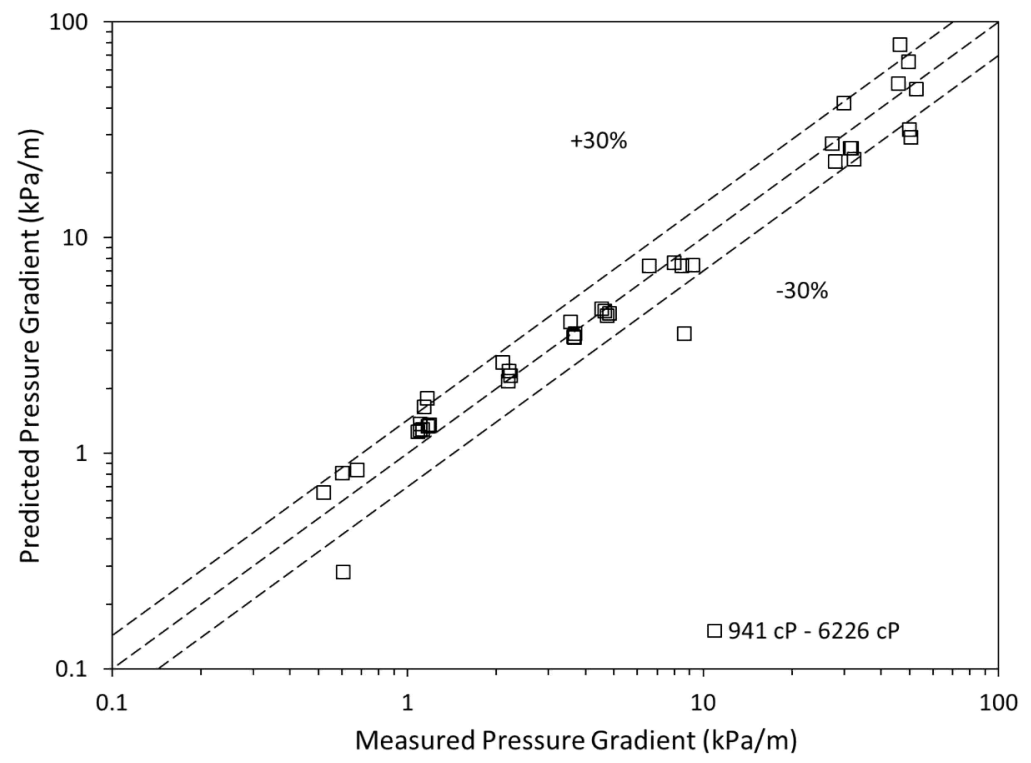

Figure 15 Pressure comparison between prediction and the present results with viscosities from $941 \mathrm{cP}$ to $6226 \mathrm{cP}$

\subsection{Liquid holdup prediction}

The mean liquid holdup is calculated using Eq.(8). Liquid viscosity effects are implicitly included in closure relations of $E_{s}, U_{b}$ and $U_{t}$. Under the interaction of 
viscosity effects on these parameters, an increasing trend in the slug mean liquid holdup with increasing liquid viscosity was observed by Nädler and Mewes (1995). In Figure 16, predicted mean liquid holdups in slug unit are compared with the experimental results obtained from Gokcal (2005). A good agreement within errors of $\pm 15 \%$ is found. The comparison with the present experimental results is given in Figure 17. An agreement with errors of $\pm 30 \%$ is found. It may also be found that model tends to under predict the mean slug unit liquid holdups at higher liquid viscosities (1000 cP to $6000 \mathrm{cP}$ ). The possible reason could be due to the significant effects of the oil film attached on the wall.

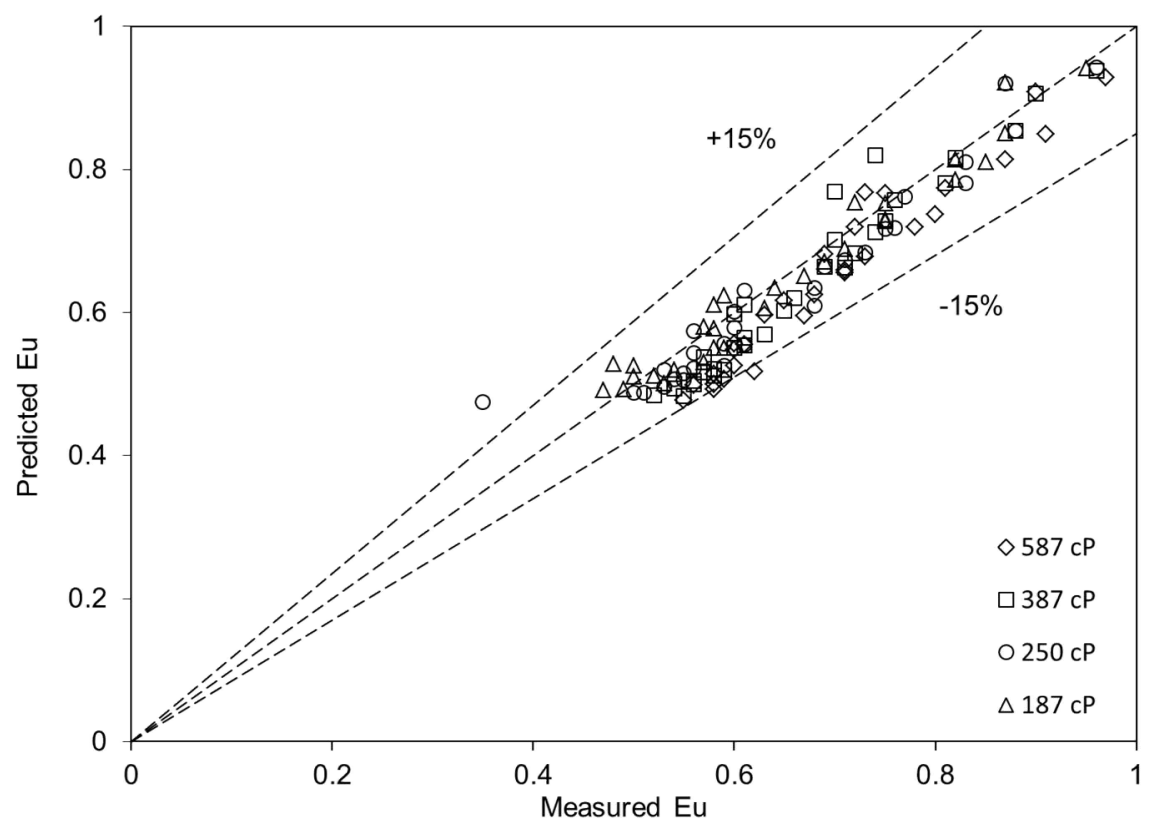

Figure 16 Comparison of predicted liquid holdup and measurement by Gokcal (2005) with different viscosities 


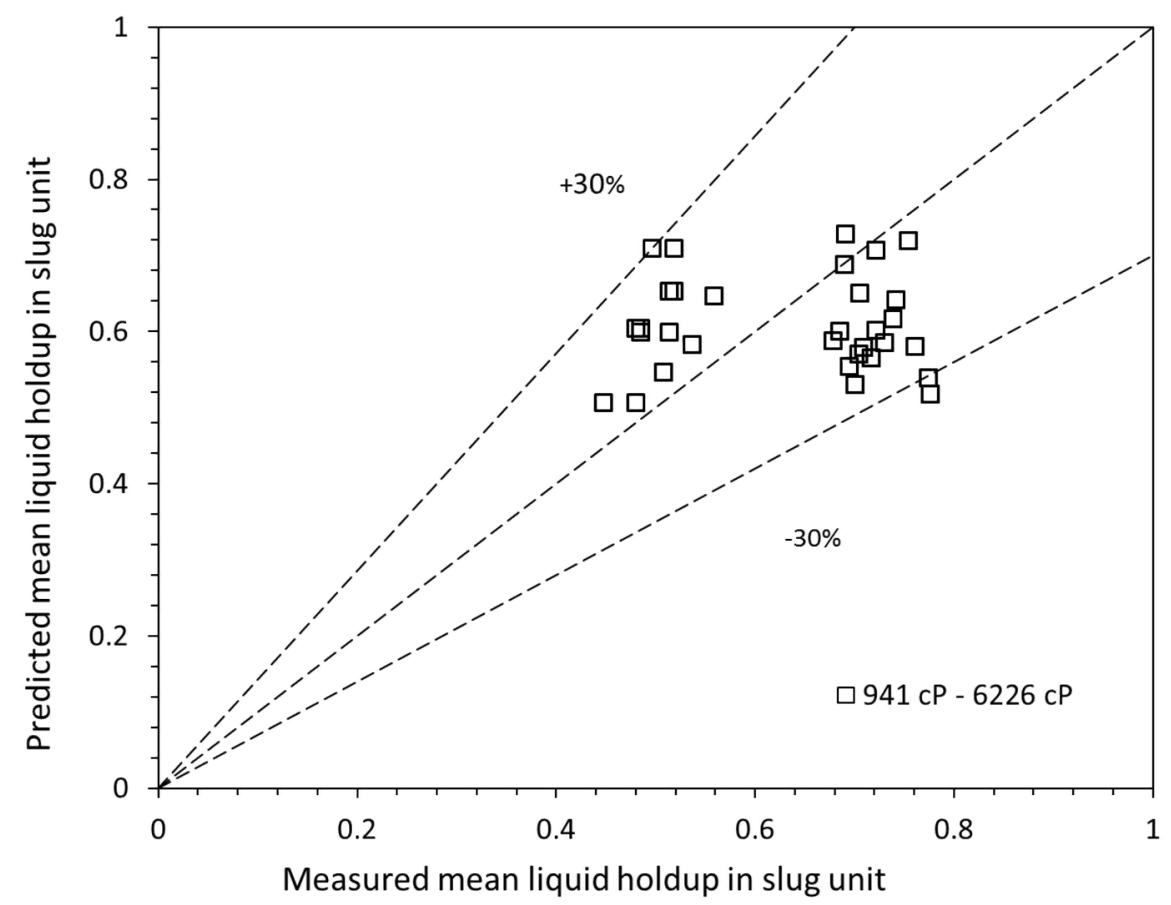

Figure 17 Comparison of predicted liquid holdup and measurement of the present experiments

\section{Conclusion}

Experiments of highly viscous liquids and gas flow are performed in a large-scale horizontal facility. Liquid viscosity effects on flow regime map, liquid holdup and pressure gradient are studied. Results of mean liquid holdup and slug body holdup, measured from high viscosity liquids and gas flow, are assessed with widely-used correlations, and the applicable models for viscous liquid and gas flow are suggested. In addition, a mechanistic slug flow model for a large range of liquid viscosity is developed. Momentum exchange between slug body and film region is considered in order to capture particular features in viscous slug flow. Closure equations are carefully chosen with consideration of liquid viscosity. The performance of this model is validated by comparing predictions of liquid holdup and pressure gradient with experimental data. Results with large viscosity ranges from 1 
$\mathrm{cP}$ to $6000 \mathrm{cP}$ are tested, and good agreements are found. However, this model still needs to be validated by additional data, not only with large ranges of liquid viscosity, but also in different pipe diameters and with various gas properties.

\section{Acknowledgements}

The authors wish to thank BP E\&P, UK and BP Alaska for the support in the construction of experimental rig in PSE lab, Cranfield University. This work has been undertaken within the Joint Project on Transient Multiphase Flows and Flow Assurance. The authors wish to acknowledge the contributions made to this project by the UK Engineering and Physical Sciences Research Council (EPSRC) and the following: ASCOMP, GL Noble Denton; BP Exploration; CD adapco; Chevron; ConocoPhillips; ENI; ExxonMobil; FEESA; FMC Technologies; IFP Energies nouvelles; Granherne; Institutt for Energiteknikk; Kongsberg Oil \& Gas Technologies; MSi Kenny; PDVSA (INTEVEP); Petrobras; PETRONAS; SPT Group; Shell; SINTEF; Statoil and TOTAL.

\section{Reference}

Abdul-Majeed, G.H., (2000).Liquid slug holdup in horizontal and slightly inclined two-phase slug flow.J.Petrol. Sci. Eng., 27, 27-32.

Al-Safran, E., Gokcal, B., Sarica,C.,(2011), High viscosity liquid effect on two-phase slug length in horizontal pipes. Presented at the $15^{\text {th }}$ International Conference on Multiphase Production Technology, Cannes, France, Jun 15-17.

Al-Safran, E., Kora, C., and Sarica, C., (2013), Prediction of liquid volume fraction in slugs in two-phase horizontal pipe flow with high viscosity liquid. Presented at $16^{\text {th }}$ Internation Conference on Multiphase Production Technology, Cannes, France, Jun 12-14.

Andritsos, N., (1986). Effect of pipe diameter and liquid viscosity on horizontal stratified flow. Ph.D. Dissertation, Dept of Chem Engineering, U. of Illinois, Urbana.

Andritsos, N., Hanratty, T.J., (1987a), Interfacial instability for horizontal gas-liquid flows in pipelines. Int.J.Multiphase Flow, 13, 583-603. 
Andritsos, N., Hanratty, T.J., (1987b), Influence of interfacial waves in stratified gas-liquid flows. AICHE.J., 33,444-454.

Andritsos, N., Williams, L., Hanratty, T.J., (1989). Effect of liquid viscosity at the stratifiedslug transition in horizontal pipe flow. Int. J. Multiphase Flow, 15, 877-892

Barnea, D., (1987), A unified model for predicting flow-pattern transition for the whole range of pipe inclinations. Int.J.Multiphase Flow, 13, 1-12.

Barnea, D., (1991). On the effect of viscosity on stability of stratified gas-liquid flowapplication to flow pattern transition at various pipe inclinations. Chem. Eng. Sci., Vol.46, 2123-2131.

Beggs, H.D. and Brill, J.P., (1973). A study of two-phase flow in inclined pipes. J. Petrol. Tech., 25(5), 607-617.

Bendiksen, K.H., (1984). An experimental investigation of the motion of long bubbles in inclined tubes. Int.J.Multiphase Flow, 13, 1-12.

Dukler, A.E., and Hubbard, M.G., (1975). A model for gas-liquid slug flow in horizontal and near horizontal tubes. Ind. Eng. Chem. Fundam., 14, 337-347.

Gokcal, B. (2005). Effects of high oil viscosity on two-phase oil-gas flow behaviour in horizontal pipes. M.S. Thesis, U. of Tulsa, Tulsa, Oklahoma.

Gokcal, B., Al-Sarkhi, A. S., Sarica, C., Al-Safran, E. M., (2009b). Prediction of slug frequency for high viscosity oils in horizontal pipes. Presented at 2009 SPE Annual Technical Conference and Exhibition, New Orleans, Louisiana, USA, Oct. 4-7.

Gokcal, B., Al-Sarkhi, A.S., and Sarica, C., (2009a). Effects of high oil viscosity on drift velocity for horizontal and upward inclined pipes. SPE Project, Facilities \& Construction, 4, 2, 32-40.

Gokcal,B., Wang,Q., Zhang,H.Q.,Sarica,C.,(2006), Effects of high oil viscosity on oil/gas flow behavior in horizontal pipes, presented at 2006 SPE Annual Technical Conference and Exhibition, San Antonio, Texas,USA, Sep.24-27.

Gomez, L.E., Shoham, O., Schmidt, Z., Chokshi, R.N., Brown, A., and Notrhug, T.,(1999). A unified mechanistic model for steady-state two-phase flow in wellbores and pipelines. Presented at 1999 SPE Annual Technical Conference and Exhibition, Houston, Texas, USA, October 3-6.

Gregory, G.A., Nicholson, M.K. and Aziz, K., (1978), Correlation of the liquid volume fraction in the slug for horizontal gas-liquid slug flow, Int. J. Multiphase Flow, 4, 33-39.

Jeyachandra, B.C., Gokcal, B., Al-Sarkhi, A., Sarica, C., and Sharma, A.K., (2010). Driftvelocity closure relationships for slug two-phase high-viscosity oil flow in pipes. Presented at SPE Annual Technical Conference and Exhibition, Tuscany, Italy, 20-22 Septermber.

Kowalski, J.E., 1987. Wall and interfacial shear stress in stratified flow in a horizontal pipe. AICHE. J., 33, 274-281. 
Marquez, J., and Trujillo, J., (2010), Overview: slug flow characterization for heavy-oil field. Presented at 2010 SPE Latin American \& Caribbean Petroleum Engineering Conference, Lima, Peru, 1-3 December.

Matsubara,H., Naito,K., (2011), Effect of liquid viscosity on flow patterns of gas-liquid twophase flow in a horizontal pipe, Int. J. Multiphase flow,37,1277-1281.

Nädler, M., Mewes, D., (1995), Effects of liquid viscosity on the phase distributions in horizontal gas-liquid slug flow. Int. J. Multiphase Flow, 21, 253-266.

Newton, C.H., Behnia,M., and Reizes, J.A., (1999), The effects of liquid viscosity on gas wall and interfacial shear stress in horizontal two-phase pipe flow. Chem. Eng. Sci., 54, 10711079.

Nicklin, D. J., (1962). Two-phase bubble flow. Chem. Eng. Sci., 17, 693-702.

Pereyra, E., Arismendi, R., Gomez, L., Mohan, R., Shoham, O. and Kouba, G., (2012), State of the art of experimental studies and predictive methods for slug liquid holdup, ASME J. of Energy Resources Tech., 134, June 2012.

Taitel, Y., Barnea, D., (1990). Two-phase slug flow. Advances in heat transfer, 20, 83-132.

Taitel, Y., Dukler, A. E., (1976). A model for predicting flow regime transitions in horizontal and near horizontal gas-liquid flow. AICHE J., 22, 47-55.

Wallis, G.B., (1969). One-dimensional two-phase flow. McGraw-Hill, New York, 1969.

Xiao, J.J., Shonham, O., Brill, J.P.,(1990), A Comprehensive Mechanistic Model for TwoPhase Flow in Pipelines. Presented at 1990 SPE Annual Technical Conference and Exhibition, New Orleans, Louisiana, USA, Sep 23-26.

Zorgani, E., Yeung, H., Fairhurst, P., Zhao, Y., Archibong, E. A., (2012). CHOPS Phase II (Cold Heavy Oil Production with Sand) Final Report, BP.

Zhang, H.-Q., Jayawardena, S.S., Redus, C.L., and Brill, J.P., (2000). Slug dynamics in gasliquid pipe flow. ASME J. Energy Res. Tech.122,14-21.

Zhang, H.-Q., Wang,Q., Sarica,C. and Brill,J.P.,(2003a), Unified model for gas-liquid pipe flow via slug dynamics-part 1:model development, ASME J. Energy Res. Tech.,125,266.

Zhang, H.-Q., Wang,Q., Sarica,C. and Brill,J.P.,(2003b), Unified model for gas-liquid pipe flow via slug dynamics part 2: model validation, ASME J. Energy Res. Tech.,125,274-283.

Zhao, Y., Yeung, H., Zorgani, E.E., Archibong, A.E., (2013a). High viscosity effect on characteristics of oil and gas two-phase flow in horizontal pipes, Chem. Eng. Sci.. 95, 343352.

Zhao, Y., Yeung, H., and Lao, L., (2013b). High liquid viscosity effects on wall and interfacial shear stresses in horizontal liquid-gas flows. Presented at $8^{\text {th }}$ International Conference on Multiphase Flow, ICMF 2013, Jeju, Korea, May 26-31. 
Nomenclature

\begin{tabular}{|c|c|c|}
\hline Symbols & Denotes & Units \\
\hline$A$ & Area & $m^{2}$ \\
\hline$C$ & Constants & \\
\hline$D$ & Pipe diameter & $m$ \\
\hline E & Liquid holdup & \\
\hline$E_{o}$ & Eotvos number & \\
\hline$F_{r}$ & Froude number & \\
\hline$G$ & Acceleration due to gravity & $m \cdot s^{-2}$ \\
\hline$f$ & Friction factors & \\
\hline$h$ & Liquid height & $m$ \\
\hline$L$ & length & $m$ \\
\hline$M$ & Momentum exchanges & $\mathrm{kg} \mathrm{m} / \mathrm{s}$ \\
\hline$N_{\mu}$ & Dimensionless viscosity number & \\
\hline$P$ & Pressure & $k P a$ \\
\hline $\operatorname{Re}$ & Reynolds number & \\
\hline$S$ & Perimeter & $m$ \\
\hline$U$ & Velocity & $\mathrm{m} / \mathrm{s}$ \\
\hline \multicolumn{3}{|c|}{ Greek letter } \\
\hline$\mu$ & Viscosity & $c P$ \\
\hline$\rho$ & Density & $\mathrm{kg} / \mathrm{m}^{3}$ \\
\hline$\tau$ & Shear stress & $P a$ \\
\hline$\alpha$ & Pipe inclination angle & $\circ$ \\
\hline$\varepsilon$ & Statistical parameter & \\
\hline
\end{tabular}

\section{Subscripts}

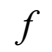

g

$i$

l

m

O

S

$t$

$u$ $m^{2}$

m

$s^{-2}$

m

$m$

$\mathrm{g} / \mathrm{s}$

$P a$

$m$

$\mathrm{m} / \mathrm{s}$

$P$

$\mathrm{g} / \mathrm{m}^{3}$

Pa 


\section{Appendix 1 Statistical analysis}

Six statistical parameters used to evaluate the performance of slug liquid holdup correlations are calculated based on relative error and actual error (Gokcal et al., 2009b):

$$
\begin{gathered}
e_{r i}=\frac{\left(E_{i, \mathrm{Cal}}-E_{i, \mathrm{Mea}}\right)}{E_{i, \mathrm{Mea}}} \times 100 \\
e_{i}=E_{i, \mathrm{Cal}}-E_{i, \mathrm{Mea}}
\end{gathered}
$$

Average percentage relative error is:

$$
\varepsilon_{1}=\frac{1}{N} \sum_{1}^{N} e_{r i}
$$

Average absolute percentage relative error is:

$$
\varepsilon_{2}=\frac{1}{N} \sum_{1}^{N}\left|e_{r i}\right|
$$

Standard deviation about average relative error is:

$$
\varepsilon_{3}=\sqrt{\frac{\sum_{1}^{N}\left(e_{r i}-\varepsilon_{1}\right)}{N-1}}
$$

Average actual error is:

$$
\varepsilon_{4}=\frac{1}{N} \sum_{1}^{N} e_{i}
$$


Average absolute actual error is:

$$
\varepsilon_{5}=\frac{1}{N} \sum_{1}^{N}\left|e_{i}\right|
$$

Standard deviation about average actual error is:

$$
\varepsilon_{6}=\sqrt{\frac{\sum_{1}^{N}\left(e_{i}-\varepsilon_{1}\right)}{N-1}}
$$




\section{Appendix 2 Model calculation procedure:}

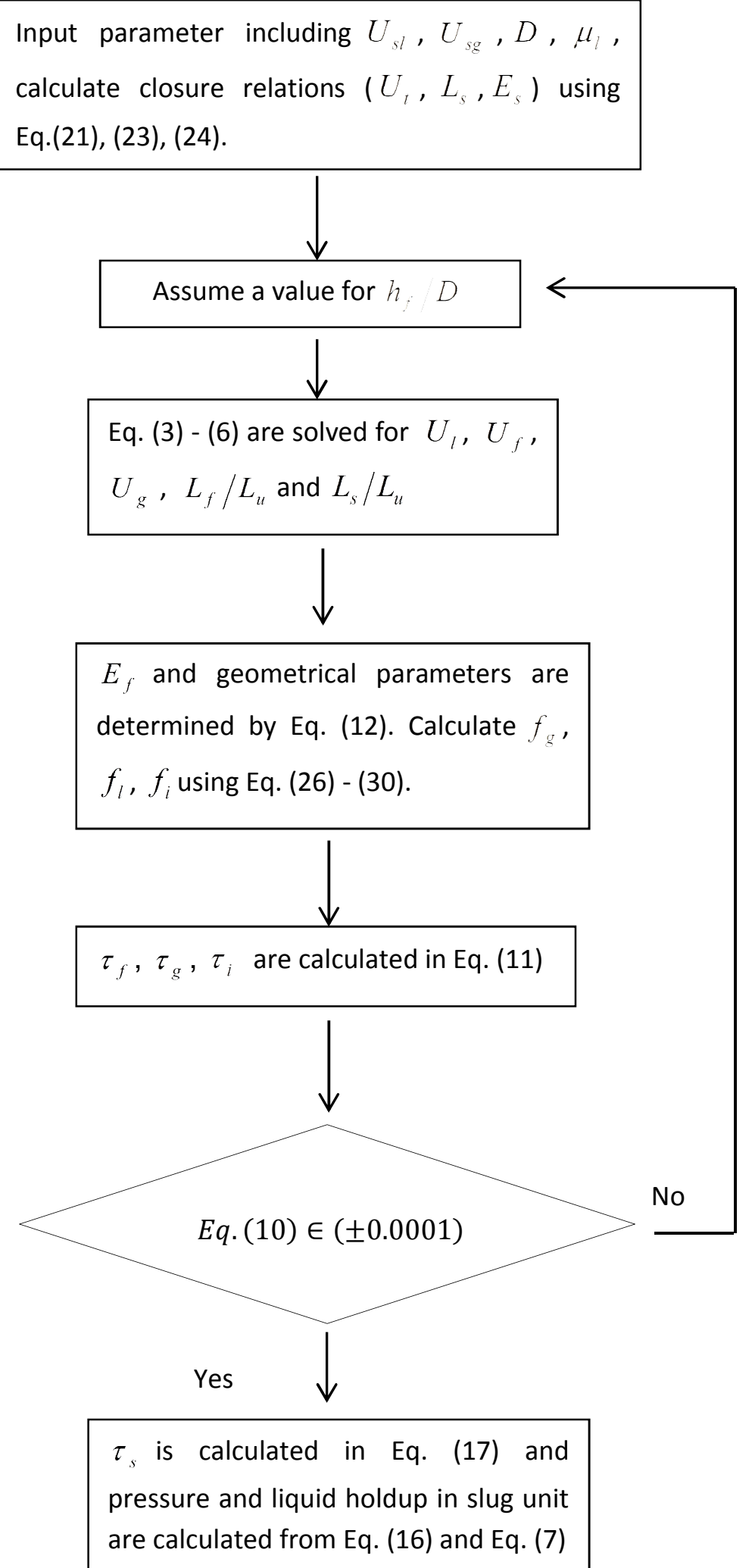

